\title{
Using Remotely-Sensed Estimates of Soil Moisture to Infer Soil Texture and Hydraulic Properties across a Semi-arid Watershed
}

\author{
Joseph A. Santanello, Jr. ${ }^{1,2}$, Christa D. Peters-Lidard ${ }^{2}$, Matthew E. Garcia ${ }^{2,3}$, David M. Mocko ${ }^{2,4}$, \\ Michael A. Tischler ${ }^{5}$, M. Susan Moran ${ }^{6}$, and D. P. Thoma ${ }^{6}$ \\ ${ }^{1}$ Earth System Science Interdisciplinary Center, UMCP, College Park, MD \\ ${ }^{2}$ NASA-GSFC Hydrological Sciences Branch, Greenbelt, MD \\ ${ }^{3}$ Goddard Earth Sciences and Technology Center, UMBC, Baltimore, MD \\ ${ }^{4}$ Science Applications International Corporation, McClean, VA \\ ${ }^{5}$ U.S. Army Engineer Research and Development Center, TEC, Alexandria, VA \\ ${ }^{6}$ USDA ARS Southwest Watershed Research Center, Tucson, AZ
}

\begin{abstract}
Near-surface soil moisture is a critical component of land surface energy and water balance studies encompassing a wide range of disciplines. However, the processes of infiltration, runoff, and evapotranspiration in the vadose zone of the soil are not easy to quantify or predict because of the difficulty in accurately representing soil texture and hydraulic properties in land surface models. This study approaches the problem of parameterizing soils from a unique perspective based on components originally developed for operational estimation of soil moisture for mobility assessments. Estimates of near-surface soil moisture derived from passive (L-band) microwave remote sensing were acquired on six dates during the Monsoon '90 experiment in southeastern Arizona, and used to calibrate hydraulic properties in an offline land surface model and infer information on the soil conditions of the region. Specifically, a robust parameter estimation tool (PEST) was used to calibrate the Noah land surface model and run at very high spatial resolution across the Walnut Gulch Experimental Watershed. Errors in simulated versus observed soil moisture were minimized by adjusting the soil texture, which in turn controls the hydraulic properties through the use of pedotransfer functions. By estimating a continuous range of widely applicable soil properties such as sand, silt, and clay percentages rather than applying rigid soil texture classes, lookup tables, or large parameter sets as in previous studies, the physical accuracy and consistency of the resulting soils could then be assessed.

In addition, the sensitivity of this calibration method to the number and timing of microwave retrievals is determined in relation to the temporal patterns in precipitation and soil drying. The resultant soil properties were applied to an extended time period demonstrating the improvement in simulated soil moisture over that using default or county-level soil parameters. The methodology is also applied to an independent case at Walnut Gulch using a new soil moisture product from active (C-band) radar imagery with much lower spatial and temporal resolution. Overall, results demonstrate the potential to gain physically meaningful soils information using simple parameter estimation with few but appropriately timed remote sensing retrievals.
\end{abstract}




\title{
Using Remotely-Sensed Estimates of Soil Moisture to Infer Soil Texture and Hydraulic Properties across a Semi-arid Watershed
}

\author{
Joseph A. Santanello, Jr. ${ }^{1,2}$, Christa D. Peters-Lidard ${ }^{2}$, Matthew E. Garcia ${ }^{2,3}$, David M. Mocko ${ }^{2,4}$, \\ Michael A. Tischler ${ }^{5}$, M. Susan Moran ${ }^{6}$, and D. P. Thoma ${ }^{6}$ \\ ${ }^{1}$ Earth System Science Interdisciplinary Center, UMCP, College Park, MD \\ ${ }^{2}$ NASA-GSFC Hydrological Sciences Branch, Greenbelt, MD \\ ${ }^{3}$ Goddard Earth Sciences and Technology Center, UMBC, Baltimore, MD \\ ${ }^{4}$ Science Applications International Corporation, McClean, VA \\ ${ }^{5}$ U.S. Army Engineer Research and Development Center, TEC, Alexandria, VA \\ ${ }^{6}$ USDA ARS Southwest Watershed Research Center, Tucson, AZ

\section{Statement of Significance} \\ Submitted to Remote Sensing of Environment \\ October 2006
}

This study examines the ability of microwave remote sensing estimates of soil moisture to be used to calibrate a land surface model and, in the process, infer soil textural and hydraulic properties across spatially heterogeneous landscapes. Results also demonstrate the limitations and potential improvements in simulating soil moisture evolution using a combination of remote sensing, modeling, and parameter estimation techniques. 
Editorial Manager(tm) for Remote Sensing of Environment

Manuscript Draft

Manuscript Number:

Title: Using Remotely-Sensed Estimates of Soil Moisture to Infer Soil Texture and Hydraulic Properties across a Semi-arid Watershed

Article Type: Full length article

Section/Category:

Keywords: parameter estimation; soil moisture; active microwave; passive microwave; PBMR; land surface modeling; model calibration; soil texture; soil hydraulic properties; temporal sampling; watershed modeling; soil type; pedotransfer functions

Corresponding Author: Dr. Joseph A. Santanello, Ph.D.

Corresponding Author's Institution: University of Maryland - College Park

First Author: Joseph A. Santanello; Ph:D.

Order of Authors: Joseph A. Santanello, Ph.D.; Christa D Peters-Lidard, Ph.D.; Matthew A Garcia, M.S.;

David M Mocko, M.S.; Michael E Tischler, M.S.; Susan Moran, Ph. D.; David P Thoma, Ph.D.

Manuscript Region of Origin:

Abstract: 


\begin{abstract}
Near-surface soil moisture is a critical component of land surface energy and water balance studies encompassing a wide range of disciplines. However, the processes of infiltration, runoff, and evapotranspiration in the vadose zone of the soil are not easy to quantify or predict because of the difficulty in accurately representing soil texture and hydraulic properties in land surface models. This study approaches the problem of parameterizing soils from a unique perspective based on components originally developed for operational estimation of soil moisture for mobility assessments. Estimates of nearsurface soil moisture derived from passive (L-band) microwave remote sensing were aequired on six dates during the Monsoon '90 experiment in southeastern Arizona, and used to calibrate hydraulic properties in an offline land surface model and infer information on the soil conditions of the region. Specifically, a robust parameter estimation tool (PEST) was used to calibrate the Noah land surface model and run at very high spatial resolution across the Walnut Gulch Experimental Watershed. Errors in simulated versus observed soil moisture were minimized by adjusting the soil texture, which in turn controls the hydraulic properties through the use of pedotransfer functions. By estimating a continuous range of widely applicable soil properties such as sand, silt, and clay percentages rather than applying rigid soil texture classes, lookup tables, or large parameter sets as in previous studies, the physical accuracy and consistency of the restilting soils could then be assessed.

In addition, the sensitivity of this calibration method to the number and timing of microwave retrievals is determined in relation to the temporal patterns in precipitation and soil drying. The resultant soil properties were applied to an extended time period demonstrating the improvement in simulated soil moisture over that using default or county-
\end{abstract}


level soil parameters. The methodology is also applied to an independent case at Walnut Gulch using a new soil moisture product from active ( $\mathrm{C}$-band) radar imagery with much lower spatial and temporal resolution. Overall, results demonstrate the potential to gain physically meaningful soils information using simple parameter estimation with few but appropriately timed remote sensing retrievals. 


\section{Using Remotely-Sensed Estimates of Soil Moisture to Infer Soil Texture and Hydraulic}

\section{Properties across a Semi-arid Watershed}

Joseph A. Santanello, Jr. ${ }^{1,2}$, Christa D. Peters-Lidard ${ }^{2}$, Matthew E. Gareia ${ }^{2,3}$, David M. Mocko ${ }^{2,4}$, Michael A. Tischler, M. Susan Moran ${ }^{6}$, and D. P. Thoma. ${ }^{6}$

${ }^{1}$ Earth System Science Interdisciplinary Center, UMCP

${ }^{2}$ NASA-GSFC Hydrological Sciences Branch, Greenbelt, MD

${ }^{3}$ Goddard Earth Sciences and Technology Center, UMBC

${ }^{4}$ Science Applications International Corporation, McClean, VA

${ }^{5}$ U.S. Army Engineer Research and Development Center, TEC, Alexandria, VA

${ }^{6}$ USDA ARS Southwest Watershed Research Center, Tueson, AZ

Submitted to Remote Sensing of Environment

October 2006 


\section{Introduction}

Soil moisture remains an essential yet elusive component of Earth system science research across a wide range of scales and applications. In addition to impacting agriculture, water resource management, and extreme events such as flooding and drought, the day-to-day variability in soil moisture on field to global seales is an important quantity for atmospheric modeling and prediction. In fact, the accuracies of climate, mesoscale, boundary layer, land surface, and hydrologic models are ultimately dependent on proper treatment and simulation of the state and transfer of water and heat at the land surface (Koster et al. 2004; Findell and Eltahir 2003; Berbery et al. 2003; Betts et al. 2003; Betts 2000).

Unfortunately, soil moisture is not as easily meastured or observed as atmospheric properties such as temperature, humidity, and wind speed. For example, in situ or remotely-sensed observations of soil moisture for initialization, update, and validation purposes are not yet available on the scales of most models. Observations are generally confined to short-term field experiments, many of which have highlighted the heterogeneous nature of soils in terms of water content and texture (Mohanty et al. 2002). Indirect estimates of soil moisture can be obtained using thermal infrared measurements (Carlson et al. 1995), but require a priori information on the surface characteristics. As an alternative, passive and active microwave remote sensing methods have had the greatest success in estimating soil moisture in a temporally and spatially consistent manner (Thoma et al. 2006; Moran et al. 2004; Hollenbeck et al. 1996).

Recent studies have noted that the most successful and promising approach to estimating soil moisture continuously over time and space must include a combination of remote sensing and modeling (Entekhabi et al. 1999; Houser et al. 1998). The majority of land surface models (LSMs) require soil hydrautic parameters to solve for the transport of moisture within the soil 
using Richards' (1931) formulations. These parameters are often derived from soil texture information, but due to the heterogeneots nature of soils and lack of detailed maps of soil properties, soil parameterization schemes are often crude, inflexible, or inappropriate. Further, LSMs have been shown to potentially be more sensitive to the choice of soil hydraulic properties or soil texture data than to atmospherie forcing or surface characteristies (Gutmann and Small 2005; Pitman 2003).

Because of these difficulties, numerous attempts have been made to optimize LSM parameters using observations of state variables such as soil moisture and surface temperature as constraints (Hogue et al. 2005; Liu et at. 2004; Hess 2001; Gupta et al. 1999). While these studies highlight the potential for parameter estimation techniques to derive large sets of 'effective' parameters and diagnose specific model weaknesses, little has been gained in terms of acquiring physically-meaningful or hydraulically consistent estimates of individual parameters. Because of the complexity and number of estimation techniques and parameter sets employed in these studies, it remains difficult to infer or derive any parameter information that could be applied to other independent studies or models.

With these issues in mind, this paper examines the potential use of passive and active microwave retrievals of near-surface soil moisture to calibrate a LSM and infer a physicallymeaningful and.consistent set of soil hydraulic parameters, using a combination of highresolution land surface modeling and parameter estimation. The experimental design of this work was originally developed for the purpose of estimating troop and vehicle mobility for the United States Army based on operational soil moisture prediction from a very limited set of input data (Army Remote Moisture System; ARMS; Tischler et al. 2006). Here, we have tested and extended ARMS to assess the ability of parameter estimation techniques to minimize inherent 
model error, yet still provide information on difficult to obtain soil properties over the Walnut Gulch Environmental Watershed (WGEW) in Arizona.

Accordingly, Section 2 summarizes the current state of knowledge of the many components of the ARMS project including soil parameterizations in LSMs, microwave remote sensing of soil moisture, and parameter estimation. In Section 3, the models, site, and remote sensing data employed in this study are described. Results of the calibration experiments are presented in Section 4, including an evaluation of the optimized parameters and sensitivity to temporal sampling of remote sensing. Finally, Section 5 discusses the limitations and applicability of the results, including suggestions for the future utility of physically meaningful parameters in LSMs.

\section{Background}

\section{a. Soil Parameterizations in LSMS}

The influence of near-surface soil moisture on the partitioning of surface turbulent fluxes from offline LSMs to fully coupled global climate models has been well-documented (e.g., Braun and Schadler 2005; Ek and Holtslag 2003; Santanello and Carlson 2001; Cuenea et al. 1996; Sun and Bosilovich 1996; Ek and Cuenca 1994; Jacobs and DeBruin 1992). In order to simulate the evolution of moisture in the soil, a set of soil hydraulic parameters are combined with expressions (known as soil moisture characteristic curves) relating soil moisture $(\theta)$ with matric potential $(\psi)$, and soil moisture with hydraulic conductivity $(K)$. The expressions derived by Brooks and Corey (1964) and Campbell (1974) are most commonly used in meteorological coupled models, while the van Genuchten (1980) functions based on a different set of soil measurements are used for more detailed soil and hydrological models. A full description and evaluation of these functions can be found in Braun and Schadler (2005). 
The three forms of the characteristic curves above depend on a set of 4 (Campbell, 1974) or 5 (Brooks and Corey, 1964; van Genuchten, 1980) hydraulic parameters, which are a function of the soil composition and structure. These parameters include the saturated matric potential ( $\psi_{s}$; aka "bubbling" of "air entry"), the saturated hydraulic conductivity $\left(K_{s}\right)$, the saturated soil moisture content (porosity; $\theta_{s}$ ), the residual soil moisture content $\left(\theta_{r}\right)$, and the pore size distribution index $(b)$. Unfortunately, estimating these parameters consistently and accurately has proven difficult even for identical soils measured under controlled laboratory conditions. Further, studies have shown that LSM simulation of soil moisture can be more dependent upon the specification of hydraulic parameters than atmospheric foreing of surface conditions (Gutmann and Small 2005; Santanello and Carlson 2001).

To mitigate these differences and acquire a somewhat standard set of parameters for LSM applications, 'bulk' parameters have been derived that are based on soil type. The results of Clapp and Hornberger (CH; 1978), Rawls et al. (1982), and Cosby (1984) and provide the most extensive and commonly employed lookup tables of hydraulic parameters for LSMs, with atmospheric-based applications favoring $\mathrm{CH}$ and Cosby and soil hydrology models employing the Rawls parameters. Unfortunately, parameter lookup tables are only as accurate as the available soil texture type information and provide an "average" value of each parameter for each soil type. High-resolution soil texture maps remain difficult to obtain, particularly on regional and global scales, and there is little flexibility between soil types or for mixed soils despite that larger differences in soil properties have been observed within a certain soil type than between types (Gutmann and Small 2005; Soet and Stricker 2003; Feddes et al. 1993).

To bridge the gap between rigid soil textural classes and the heterogeneous nature of soils, numerous pedotransfer functions (PTFs) have been developed (Sobieraj et al. 2001). The most 
commonly used 'class' PTFs relate discrete soil types to hydraulic parameters and are the basis upon which lookup tables are used in LSM and meteorological modeling applications. 'Continuous' PTFs are more detailed and relate measurable soil properties such as percent of sand and clay, porosity, and bulk density to hydraulic properties using regression equations derived from soil samples. These functions are continuous without bounds, and therefore allow more flexibility and independence in parameter values than those from lookup tables, More importantly, continuous PTFs that are able to reproduce areal averaged conditions in LSMs have been shown to scale linearly in space and therefore could be used to infer spatially-aggregated hydraulic parameters. Although the advantages of continuous over elass PTFs has been demonstrated for hydrologic models (Soet and Stricker 2003), continuous PTFs are not routinely employed in LSMs (except for CLM, give reference) or atmospheric models where the broad definition and application of soil types still dominate the simulation of soil moisture.

\section{b. Parameter Estimation}

An alternative to specifying highly-uncertain soil hydraulic parameters in LSMs is to use parameter estimation and model calibration techniques. For example, a relatively simple and well-established parameter estimation model (PEST; Doherty 2004) has been used by a number of scientific disciplines to optimize model parameters given limited observations of fundamental output variables. For example, by adjusting soil porosity in a LSM until the difference in simulated versus observed soil moisture is minimized (through a specified objective function), an LSM can be calibrated using PEST.

In recent years, more sophisticated estimation techniques have been developed to estimate large and diverse sets of parameters. Liu et al. (2003) used a multi-objective technique for offline and partially-coupled LSMs to examine the pathways by which a deficiency in the model 
physics impacts coupled and uncoupled simulations. Following this work, Liu et al. (2004) performed controlled parameter estimation studies of offline and partially-coupled models and examined the effects of including atmospheric (in addition to soil and vegetation) parameters in the optimization. Hogue et al. (2005) investigated the transferability of large optimized parameter sets in an offline LSM across varying surface conditions and time periods, and concluded that parameter optimization needs to be site-specific for best results, and should be recalibrated for changes in seasons or over longer time intervals.

Scott et al. (2000) performed soil hydraulic parameter estimation using the Hydrus soil moisture model at two sites in the Walnut Gulch Environmental Watershed (WGEW) in Arizona. While the focus was on the vertical distribution of soil moisture and recharge at these points alone, their results show that the model was least sensitive to $K_{\text {sat }}$ and most sensitive to porosity and $b$, which is consistent with other studies. Scott et al. (2000) also stress that the derived parameters are 'effective' in nature, compensating for errors in the soil physies of the model, and that further research is needed to assess the limitations of parameter estimation across spatially heterogeneous and distributed watersheds.

Overall, parameter estimation studies have focused on large sets of parameters and complex algorithms that require a great deal of computational time. From these studies, it could also be argued that the bulk of the work done to this point has been focused on 'model calibration' rather than parameter estimation, particularly when there is significant model error accounted for in the optimized parameters. It is important to note that the research presented here differs from such multi-objectives techniques, and is focused solely on calibrating a physically meaningful set of soil hydraulic properties that improve soil moisture simulated by a LSM.

\section{c. Remote Sensing of Soil Moisture}


Due to the limited nature of available soil instrumentation and measurement techniques (e.g., theta probe, TDR, Vitel probe, gravimetric), a spatially continuous and reliable network of soil moisture measurements that could be used to imitialize and evaluate LSMs does not exist. As a result, passive microwave ( $\mathrm{L}$-band; $1.4 \mathrm{GHz}$ ) estimation of soil moisture has been has been explored a great deal using instruments such as NASA's push broom microwave radiometer (PBMR; Schmugge et al. 1988). Due to the high spatial resolution required at this wavelength $(21 \mathrm{~cm})$, passive microwave radiometers are typically flown on aircraft where they have shown a great deal of promise in estimating soil moisture across varying surface conditions (Mattikalli et al. 1998; Burke et al. 1997; Hollenbeck et al. 1996). Changes in the dielectric constant the top 5 $\mathrm{cm}$ of soil are due to changes in the relative water content, and are evident in the brightness temperature measured by the sensor.

More recently, techniques have been developed to estimate soil moisture using active microwave remote sensing (C-band; 5.3 GHz). Because of the shorter wavelength $(5.6 \mathrm{~cm})$, active sensors can placed aboard satellite platforms and potentially acquire high resolution estimates of soil moisture when combined with empirical and physical models (Thoma et al. 2006). To date, there have been mixed results using radar remote sensing to estimate soil moisture due to the sensitivity of low frequency backscatter to the nature and degree of surface interactions and, consequently, the degree of signal correction required (see also review by Moran et al. 2004).

Recently, Thoma et al. (2006) have developed an image differencing technique for active remote sensing that shows promise in eliminating much of the noise in $\mathrm{C}$-band radar data. This 'delta index' method requires a single reference (dry) image to compare with a separate (wet) image over the same domain (assuming no other changes in surface characteristics), thereby 
isolating the change in backseatter due to soil moisture variations. This method acts to minimize errors due to surface roughness effects using filtering techniques to reduce the amount of speckle that is common in radar imagery (particularly in regions of high rock fragment).

The delta index is defined as follows,

$$
\text { delta index }=\left|\frac{\sigma_{w e t}-\sigma_{d r y}}{\sigma_{d r y}}\right|
$$

where $\sigma_{d r y}$ is the backscatter (db) from a dry radar image, and $\sigma_{w e t}$ is the radar backscatter (db) from the identical pixel location in a wet image. The delta index has been shown to have a near linear (1:1) relationship with volumetric soil moisture, and is particularly applicable to semi-arid regions where a spatially-uniform dry reference image can be acquired (Thoma et al. 2006).

\section{d. Estimation of Soil Hydraulic Properties}

Since the development of $L$-band passive microwave soil moisture retrievals, numerous studies have attempted to use a combination of remote sensing imagery, LSMs, radiative transfer (emission) models, and observations to infer soil hydraulic properties. For example, van de Griend and O'Neill (1986) demonstrated that independent measurements of soil moisture from mierowave remote sensing and the thermal inertia of the soil can be related to hydrologic properties of loamy sand soils during an 11-day dry down period. This work was extended by Camillo et al. (1986) using a combination of models and measurements for three distinct soil types under highly controlled plot-scale conditions. They calibrated a soil model (hydraulic properties) until a coupled microwave emission model best matched the observations of $\mathrm{L}$-band microwave brightness temperature over a 3-day drydown. Overall, Camillo et al. (1986) suggest that a wider range of soil moisture conditions than those observed here may improve results by better capturing the functional drying curves represented by the soil model parameterizations. 
Following the work of Camillo et al. (1986), Burke et al. (1997) and (1998) used a coupled land surface-microwave emission model in conjunetion with radiometer measurements to infer soil properties for bare and vegetated soil plots. Performed over a 10-day period with a primarily sandy soil and bare soil, corn, and soybean canopies, hydraulic parameters were adjusted to match the emission model output with L-band radiometer measurements. In agreement with other studies, the model was found to be least sensitive to $K_{\text {sat }}$ and most sensitive to $b$, and for the corn and soybean plots vegetation parameters such as leaf area index and root density were significant. Overall, these laboratory and point-scale studies point towards the future use of PTFs rather than a one-at-a-time parameter estimation approach to acquire spatially-distributed soil properties over watersheds, and suggest that an intensive period of microwave images be acquired to capture signifieant soil drydowns.

Feddes et al. (1993) examined the use of microwave measurements of soil moisture, temperature, and albedo to calibrate and infer soil hydraulic properties. They found that the 'effective' soil parameters for the LSM could be derived using this approach. However, their method also required a great deal of measurements and parameters, such as evaporation and insitu soil moisture at multiple depths, thereby limiting its application to highly controlled and plot-scale experiments.

Hollenbeck et al. (1996) used PBMR estimates of soil moisture to infer soil conditions during large-scale field experiment at HAPEX-Sahel. Two PBMR brightness temperature images, two days apart, were used to calculate the relative change in soil moisture following a precipitation event to infer soil hydraulic properties over the watershed. Though their restlts were entirely based on qualitative image-differencing, they were able to isolate the impact of soil properties on the image differences versus that of initial soil moisture, land cover, and rainfall 
distribution. The impact of antecedent precipitation is suggested for further study, as it greatly impacts the stage of soil drying being monitored by the PBMR.

Finally, Mattikalli et al. (1998) tested the laboratory results of Ahuja (1993), who demonstrated that $K_{\text {sat }}$ could be derived using remotely sensed estimates of 2-day changes in soil moisture. They concentrated on calibrations of a hydrologic model for 3 layers of soil moisture and parameters across 13 sites in the Little Washita, OK watershed. A significant qualitative correlation between spatial maps of brightness temperature, soil moisture, and soil texture give validity to the strong relationships between microwave measurements and soil type and properties for this region. Although treatment of the remaining hydraulic parameters, spatial distribution of $K_{\text {sat }}$ or a detailed evaluation against typical $K_{\text {sat }}$ values was not presented, this study confirms the theoretical framework by which a more comprehensive approach to estimating these parameters can be based.

\section{e. Summary}

These studies have demonstrated that the strong link between microwave remote sensing and soil moisture (that is ultimately controlled by hydraulic parameters) can provide a pathway to improve LSM soil physics and parameterizations. While these works have provided a strong physical and methodological foundation by which to address these issues, each has limitations in terms of scope and applicability that can now be improved upon by taking the suggested next steps and utilizing new approaches and data. Specifically, this paper will bridge the gaps between and extend previous studies by:

1) Determining the ability of parameter estimation to calibrate a LSM and to infer physically meaningful estimates of soil hydraulic properties using pedotransfer functions and microwave remote sensing of soil moisture at high spatial and temporal resolution; 
2) Testing the sensitivity of the calibration process and retrieved properties on precipitation and soil drydown patterns using temporal sampling of remote sensing imagery; and

3) Applying the retrieved soil parameters to an independent dataset, and assess the ability of a new image differencing technique of estimating soil moisture from active microwave remote sensing to be used in the calibration process.

\section{Methodology and Data}

\section{a. ARMS Background}

The Army Remote Moisture System (ARMS; Tischler et al. 2006) project is an ongoing collaboration between the U. S. Army Corps of Engineers, U. S. Department of Agriculture, NASA-GSFC, and the University of Wyoming. The goal of this work is to provide improved operational estimates of soil moisture and hydraulic properties as inputs to decision-making models based on factors such as troop and vehicle mobility and landing strip suitability. The three main components of ARMS are 1) high-resolution microwave remote sensing of soil moisture, used to calibrate a 2) land surface model by optimizing hydraulic properties through 3) parameter estimation. The ultimate goal of ARMS is to be able to use limited site information and radar-based soil moisture retrievals to calibrate an LSM for any location in the world and enable soil moisture and properties to be more aceurately simulated going forward. While this study is focused on a semiarid testbed in Arizona, ARMS is also being tested at other diverse locations across the U. S. (OK, GA, and CO).

\section{b. Site Information}

The Walnut Gulch Experimental Watershed (WGEW) is a located in southeastern Arizona, covering $148 \mathrm{~km}^{2}$ of semi-arid grassland and shrub covered rangeland. The detailed instrumentation and long record length of the datasets available in this region have made the 
WGEW the focus of many hydrological, meteorological, and remote sensing studies. Most notably, the Monsoon '90 field experiment (M90; Kustas et al. 1991) was conducted in this region in July and August of 1990, and included the deployment of eight Metflux sites across the watershed that measured standard meteorological data as well as land cover, soil moisture, and soil property information. (Fig. 1)

Overall, the conditions throtghout the WGEW are dominated by the stmmer monsoon Season of July and August, when the bulk of the annual $250-500 \mathrm{~mm}$ rainfall (mainly convective) occurs. Rainfall events during the monsoon period are typically $<10 \mathrm{~mm}$ and only influence the top $10 \mathrm{~cm}$ of soil before being quickly returned to the atmosphere through ET within 3 days (Kurc and Small 2004). This means that the near-surface soil moisture is the only variable reservoir of moisture in this region. During the period from April-July, the soils often reach a desiceated state before the onset of the monsoonal precipitation. Land cover consists mainly of open shrubland $(<30 \%$ cover $)$ in the western half of the WGEW, and grass cover $(<50 \%$ cover $)$ in the east.

At each Metflux site, standard meteorological variables were measured at 20 -minute intervals. Precipitation measurements were derived from a dense 98-gauge network covering the entire watershed, from which spatially interpolated rainfall estimates (useful for modeling applications) have been generated using a variety of techniques (Garcia et al. 2006; Houser et al. 1998). Two supersites were furnished with additional instrumentation: Lucky Hills (LH) located in the shrub dominated north-central part of the domain, and Kendall located in the grasslands of the east. Soil moisture in the upper $5 \mathrm{~cm}$ layer was estimated at each site using multiple gravimetric measurements, and vertical profiles of soil moisture were estimated at Kendall and LH using time domain reflectrometry, giving estimates from $5-50 \mathrm{~cm}$ in depth. 
In addition to the M90 period, extensive meteorological and flux measurements at the LH and Kendall sites and co-located precipitation and soil moisture measurements at the rain gauge stations have been acquired for the 2002-2004 period. This dataset is temporally more extensive than that of M90 and provides an independent dataset to evaluate LSM simulations as well as new remote sensing data and parameter estimation techniques.

\section{c. Remote Sensing of Soil Moisture}

Passive microwave remote sensing measurements $(\mathrm{L}$ band; $21-\mathrm{cm})$ of brightness temperature were made over a significant portion of the WGEW during the M90 experiment using NASA's push broom microwave radiometer (PBMR). As mentioned, the PBMR has been used extensively for measuring soil moisture across arid and semi-arid regions. Flights taken during the Monsoon '90 experiment are described in detail in Schmugge et al. (M90; 1994), and during the Hydrologic Atmospheric Pilot Experiment in 1992 (HAPEX-Sahel; Hollenbeck et at. 1996). From this dataset, six daily estimates of near-surface soil moisture are available both before (DOY 212) and after (DOY 214, 216,217, 220, and 221) the onset of precipitation. The PBMR data was resampled to $40 \mathrm{~m}$ resolution and mapped to a UTM grid that covers a subset of the WGEW that includes all 8 Metflux sites. Schmugge et al. (1994) showed that brightness temperature measurements correlated well with both rainfall and $0-5 \mathrm{~cm}$ soil moisture measured at the sites. Figure 2 shows the PBMR and gravimetric estimates of soil moisture at the Kendall and LH sites along with gauge-interpolated precipitation during the M90 period. These plots highlight the desiceated soil conditions before the first and most intense rainfall event on DOY 213, and more importantly how the PBMR images captures the period of rapid soil drying thereafter. 
For the $2002-4$ period active, or radar, microwave remote sensing (C band; $5.6 \mathrm{~cm}$ ) measurements were acquired from RADARSAT-1 imagery. A reference (dry) image was taken on 19 January 2003 and combined with images during the monsoon period (29 July, 22 August, and 15 September 2003) to derive soil moisture using the delta index approach (Eqn. 1). The three resulting $0-5 \mathrm{~cm}$ soil moisture estimates cover a 6 week period spanning an extended (seasonal) drydown period immediately following rainfall. The nominal resolution of RADARSAT-1 is 7 meters and covers the entire WGEW domain, but the raw backscatter data was further processed and filtered as discussed by Thoma et al. (2006) to 210 and 280 meter resolution to reduce the effects of speckle.

\section{d. LSM}

The Noah land surface model (Chen et al. 1996) was originally developed from the land component of the Oregon State University 1-D planetary boundary layer model (OSU; Mahrt and Ek 1984), and is currently employed as the land surface scheme in NCEP's operational version of the Weather Research and Forecasting nonhydrostatic Mesoscale Model (WRFNMM). Extensive evaluations and discussion of the Noah physies and comparisons to other LSMs has been performed by Robock et al. (2003) among others. The hydrology within the Noah model is handled by a Richard's equation formulation governed by the Campbell functions (1974). Hydraulic parameters are typically estimated from prescribed soil types based on the lookup tables and regression results of Cosby et al. (1984). Noah is typically used across a wide range of scales offline and for meso- to global-scale meteorological applications when coupled with atmospheric models.

The offline version (2.6) of Noah was configured to run at $40 \mathrm{~m}$ resolution over the WGEW. Forcing data was aequired from the LH site and applied uniformly to each pixel within the 
domain including downward shortwave and longwave radiation, air temperature, specific humidity, and wind speed at a specified reference height $(6 \mathrm{~m})$, and surface pressure. As suggested by Houser et al. (1998), the impacts of using of a single forcing dataset applied to the entire watershed are minimal so long as spatially distributed precipitation is accounted for, which is the case here. Indeed, simulations were performed using the Kendall forcing data in place of LH, and resulted in changes in surfaces fluxes that were less than the instrument error. To ensure that the most detailed precipitation data was included, rainfall from 84 of the 98 -gauge network was broken down and interpolated in time and space at 20 -minute and 40 -meter resolution. Garcia et al. (2006) provide a detailed description and evaluation of two methods of interpolating raingauge data over the WGEW, and for the large number of gauges available here both the inverse distance weighting (IDW) and multi-quadric biharmonic (MQ-B) schemes work equally well for precipitation interpolation.

In Noah, vegetation parameters for each grid cell are derived from land cover maps (using lookup tables). In a similar manner, ten soil parameters are typically derived at each grid cell from soil texture maps from the Food and Agricultural Organization of the United Nations (FAO; FAO-UNESCO 1984), State Soil Geographic Database (STATSGO; USDA 1994), or Soil Survey Geographic Database (SSURGO; USDA 2002) datasets. Mocko et al. (2006) performed a thorough evaluation of the impacts of varying inputs of land cover, soil type, and precipitation on soil moisture simulations. In this study, we use the best available land cover data (UMD; Hansen et al. 2000), climatologically-derived values of albedo and vegetation fraction, and MQ-B precipitation forcing as input to the Noah model.

A standard 4-layer soil profile was used in Noah with a top layer of $5 \mathrm{em}$ that matehed the representative depth of in-situ and remote sensing soil moisture measurements. The sensitivity 
of Noah to varying numbers (up to 20) and depths of soil layers was examined in detail, and results showed that adding additional layers and adjustment of vegetation rooting depth did not significantly alter or improve results for this semi-arid region. Also, after careful calibration with observed soil moisture values in the WGEW and the results of previous studies (Scott et al. 2000), the prescribed minimum value of soil moisture in Noah (i.e. wilting point) was lowered from 0.05 to $0.02 \mathrm{~m}^{3} \mathrm{~m}^{-3}$.

In an effort to ensure consistency and add flexibility within soil types and hydraulic parameters, PTFs were incorporated into Noah for this study. Specifically, the PTFs derived by Cosby et al. (1984) require only percentages of sand and clay to derive the hydraulie parameters, which are then independent of soil texture classes or averaging. As discussed, previous studies have pointed to the potential advantages of PTF approaches over discrete soil types and lookup tables in LSMs. Though based on the identical soil samples and data of the default Noah lookup tables, these PTFs ensure that a full range of soil parameter values based on soil composition are derived in a realistic and consistent manner.

\section{e. Parameter Estimation}

The Parameter Estimation model (PEST; Doherty 2004) is a widely-used tool for examining sensitivities and estimating parameters in models spanning a wide range of applications. In particular, the ability of PEST as a model-independent estimation technique to link with any type of LSM using flexible parameter, observation, and convergence criteria make it optimal for use in this study. Here, PEST was configured to run as a parent model to Noah (PEST-Noah), where it evaluates and minimizes an objective function based on the differences between simulated and observed soil moisture as follows

$$
R M S E=\left[\frac{1}{N_{o b s}} \sum_{i=1}^{N_{o b s}}\left(\theta_{i, \text { Noah }}-\theta_{i, P B M R}\right)^{2}\right]^{0.5}
$$


where $N_{a b s}$ is the number of PBMR observations used in the calibration and $\theta_{i, N o a h}$ and $\theta_{i, P B M R}$ are Noah simulated and PBMR observed 0-5 cm soil moisture at each observation time. Until the convergence criteria are met, PEST iterates and adjusts the Noah parameters (sand, silt, and clay percentages), evaluates if this deereases the model error, and adjusts the parameters accordingly. Extensive testing of PEST-Noah has shown that there can be on the order of 2-20 optimizations requiring up to 200 model runs before PEST converges in some cases, depending on how far apart the initial parameters are from their optimal values.

To ensure the accuracy and repeatability of PEST-Noah simulations, synthetic twin experiments were conducted. A single (control case) Noah simulation of the M90 period with preseribed sand, silt, and clay values was performed, from which the $0-5 \mathrm{~cm}$ soil moisture output was extracted on six dates corresponding to the PBMR observations. PEST-Noah was then run using Noah soil moisture output (in place of PBMR) as observations until the optimized sand, silt, and clay percentages were found. This process was repeated at the Kendall and LH sites using vastly different soil textures and moisture contents, and in each case PEST-Noah returned the precise sand, silt, and clay values prescribed in the control case. This gives confidence that PEST-Noah can be run for a variety of conditions at WGEW and that the results are unique.

\section{Results}

\section{a. M90 Calibration Experiments}

Simulations were performed during the M90 period from 23 July - 9 August 1990 that encompasses the 6 PBMR overpasses. This period allows ample time for the model to equilibrate to the very dry initial conditions leading up to the first PBMR image ( 31 July), and before the onset of the monsoon and the first significant precipitation event of the season ( 2 
August). The model was run using a 20 -minute timestep, and output was generated every six hours.

\section{i. Metflux Sites}

PEST-Noah was run at each of the 8 Metflux sites using the closest 40m PBMR pixel to each site on the 6 observation dates. Figure 3 shows the simulated soil moisture at the Kendall and LH sites before (FAO soils) and after (PEST) calibration of sand, silt, and clay along with corresponding PBMR and in-situ gravimetric measurements. Despite the differences in magnitude and drydown patterns exhibited between the sites, PEST is able to fit the simulated soil moisture to the observations. Also evident is the significant improvement in simulations using calibrated soil properties compared with those from default lookup table approach.

The RMSE and bias in simulated versus observed (PBMR) soil moisture for all 8 Metflux sites are shown in Figure 4. The ARMS requirement of 5 percent (volumetric) accuracy in soil moisture prediction is easily satisfied at all the Metflux sites when using the PEST-Noah calibration, with overall RMSE and bias values less than 2 percent. In particular, the bias in the default Noah simulation using FAO soils bas been greatly reduced using PEST to near zero for most locations. Examination of each individual site's improvement in simulated soil moisture (similar to that shown in Figure 3) makes it clear that PEST-Noah primarily acts to reduce the bias by adjusting the overall magnitude and dynamic range (using soil texture) to match observations.

Given the accuracy of the calibrated soil moisture at each site, it is useful to assess the potential utility and accuracy of optimized soil textures as well. Figure 5 shows a comparison of the optimized sand, silt, and clay pereentages at each site versus those measured during the M90 experiment by Schmugge et al. (1994). The optimized soil textures suggest a primarily sandy 
soil, and are similar to the observed soils with greater than 65 percent sand and less than 10 percent clay content. Optimized values of silt content are lower than those observed, but this is likely due to the setup of PEST-Noah where silt is actually a dummy variable and, more importantly, that the PTFs are only a function of sand and clay content. Therefore, adjusting silt in the simulations had zero impact on the soil moisture and value of the objective function evaluated by PEST.

It is also important to consider the range and magnitude of hydraulic properties resulting from the different soil textures. Table 1a presents the optimized values of sand, silt, and clay for the Metflux sites and corresponding hydraulic properties derived from the PTFs in Noah. For comparison, Table $1 \mathrm{~b}$ lists observed soil textures from Schmugge et al. (1994) and the North American Monsoon Experiment (NAME; Higgins et al. 2006) (sites 1 and 5 only), and hydraulic properties estimated using the Noah PTFs. Overall, there is relatively little variation in properties estimated from PEST-Noah across the sites despite variation in sand content (73-100 percent). Similarly, hydraulic properties derived from observed textures exhibit a small range, although their magnitude differs slightly from the PEST-Noah values due to the lower sand percentage $(66-80$ percent):

PEST-Noah suggests a slightly more sandy soil over the region than observed, but the differences in the parameters that control the soil moisture dynamics are not as significant as the soil textures might indicate. Plausible values are estimated by PEST-Noah for each parameter when compared with observations (even at site 7 where an estimate of 100 percent sand may not appear physically realistic, but the resulting properties are within measured values). This is due to the slowly varying relationships between soil texture and hydraulic properties for high sand contents governed by the PTFs. 
Evidence that the spatial differences in soil texture from PEST-Noah also have physical meaning is present in Fig. 5 and Table 1. For example, sites 2 and 7 are the extremes in optimized soil textures from lowest $(72$ percent) to highest $(100$ percent $)$ sand percentage. Measurements at these sites also support that site 7 is sandiest, and site 2 has the highest mixture of silt and clay. PEST-Noah follows the same trend at site 2, estimating a significant silt percentage which, in effect, allows the sand percentage to be lower. Inspection of the soil drying patterns observed at these sites during M90 confirms that at site 2 there is higher overall soil moisture and a more consistent but slow drydown compared with site 7 . These characteristics and subtle differences in the drying curves are responsible for PEST-Noah estimating a less sandy soil at site 2 , which is representative of the observed local soils.

To get a better feel for the physical applicability of the parameters themselves, Table 2 presents hydraulic parameters derived from FAO, STATSGO, and SSURGO soil lookup tables, a neural network-based PTF (ROSETTA; Schaap et al. 1998), PEST-Noah using PTFs, and measurements made during 2002 (Schaap and Shouse, 2004) and 2004 (NAME). The FAO soil type for all 8 Metflux sites is sandy loam, STATSGO is loamy sand, and the finer resolution SSURGO data indicates 3 different soil types across the Metflux sites. As a result, there is significant disagreement in hydraulic properties amongst these lookup tables alone.

The PEST-Noah parameters fall within the range of established datasets and measurements, yet there remain significant differences between lookup table and calibrated hydraulic properties. This is due to the ability of the PTF approach in Noah to result in a unique (but realistic) soil type that rigid lookup tables cannot describe. The ROSETTA PTF model suggests parameters that are inconsistent for a sandy soil and with observations, and indicate this particular PTF may not be appropriate for this region. Based on the improvements in simulated soil moisture 
exhibited by PEST-Noah presented earlier, the PEST-Noah soil textures and PTFs appear to be the most accurate.

It is also important to note that the large spread of hydraulic properties across data sources in Table 2 is a function of differences in way each property is estimated and what each represents. For example, $K_{\text {sat }}$ values of $250 \mathrm{~cm} \mathrm{~d}^{-1}$ (NAME 2004) are estimated from soil samples under laboratory conditions, even though actual precipitation rates could never be high enough to observe similar saturation values in the field. Further, while the ROSETTA model suggests values for $K_{\text {sat }}$ that are an order of magnitude lower than those calculated in the laboratory (and may be closer to a true saturated value observed in nature), such values result in inaccurate simulations of soil moisture when employed in Noah. Overall, it is the combination of an accurate soil type representation that ereates the range and scaling of hydraulic properties and the physies of the LSM that determines the most appropriate parameters in this case.

PEST-Noah suggests a unique soil type that also corresponds well with observations (Table $2 ; K_{\text {sat }}$ and $\theta_{s}$ ). Although the model is not perfect, the limitations of the Noah soil physics are not significant enough to deter estimates of physically meaningful soil properties. On the contrary, previous attempts at model calibration in the region have yielded parameter values that lie well outside measured values, and as such could only be interpreted as 'effective values' that absorb significantly more inherent model or forcing data deficiencies than they do represent real soil properties. For example, Scott et al. (2000) found values of $2.5 \times 10^{-6}$ and $3.7 \times 10^{-7} \mathrm{~ms}^{-1}$ for $K_{\text {sat }}$ and 0.25 and $0.23 \mathrm{~m}^{3} \mathrm{~m}^{3}$ for porosity at Kendall and LH, using a model calibration approach. Using the PTFs, these $K_{\text {sat }}$ values correspond to a soil texture of 39 percent sand, and the porosity values are so low that a soil type cannot even be derived. 
From a broader perspective, it is important to assess whether PEST-derived soil parameters can be employed in Noah and represent conditions at WGEW over longer timescales. Therefore, the soil textures optimized from the M90 period were used to run Noah at Kendall and LH over the 2002-4 evaluation period. Figure 6 shows the soil moisture simulated by PEST-Noah over a 54-day period in the summer of 2003 compared with in-situ observations from Vitel probes surrounding LH and Kendall. Simulations with optimized parameters (RMSE $=2.4 / 2.7$, Bias $=-$ 0.7/-1.9 percent for LH and Kendall) perform remarkably well compared to those using FAO soils $($ RMSE $=5.7 / 13.9$, Bias $=5.6 / 13.3$ percent $)$ over the extended period encompassing numerous precipitation and drydown events. Once again, this highlights the ability of PEST to adjust the dynamic range of soil moisture simulated by Noah and effectively respond to precipitation events, and stpports the use of optimized soil properties across this watershed for seasonal (and longer) durations.

\section{b. Temporal Sampling of PBMR Images}

The high temporal resolution of the PBMR imagery captures a complete soil drying cycle for this region. To assess the broader applicability of the methodology described above, it is useful to look at precisely how many and which PBMR images are needed for accurate calibration. The sensitivity of PEST-Noah to the number of PBMR observations was tested by testing at all possible combinations of image in the calibration process. Figure 6 a shows the error in simulated versus observed soil moisture at Kendall for each of the image combinations used in PEST-Noah. Kendall was chosen as a representative site because it exhibits the largest range of soil moisture throughout the period and also was more difficult to calibrate due to 2 significant precipitation events and a strong drydown in between. 
These results show that there is a significant reduction in RMSE (and standard deviation) once three or more images are used in the calibration. There are fewer number of data points for single images because many of those simulations were unable to converge with only one observation. What is also evident is there is a large amount of scatter or variability when using one or two images, but for three or greater all the points collapse indicating that it does not matter which images are included. Note that the error using Noah with FAO soils is over 2 times larger than even the worst PEST-Noah simulations using a single PBMR image.

The other main factor in the success of PEST-Noah is what portion of the soil drying curve (i.e. dynamic range) is captured by the PBMR images. Figure $6 \mathrm{~b}$ shows the error in simulated soil moisture against the range in soil moisture captured by the image combinations described above. The results look similar to Fig. 6a, and suggest that errors are significantly reduced if the images used capture at least 5 percent (volumetric) variability in soil moisture during a drydown period. When the full dynamic range in soil moisture is captured by the PBMR images, the RMSE and bias (not shown) in PEST-Noab simulations are minimized, and are $\sim 5$ times lower than using FAO soils.

Analyses also indicate that the second PBMR image (day 214) is the most critical observation to include in the calibration. This image was acquired immediately following a rainfall event (Fig. 1a) and represents the maximum value of soil moisture during the period. Out of the 7 simulations when PEST-Noah was unable to converge on a solution (i.e. not enough information was coming from the observations), all occurred when day 214 was not included. More importantly, out of the simulations using 5 out of 6 images, the only one unable to converge was with day 214 omitted. Error analyses (not shown) also support the importance of including day 214 , and the improvement in calibrations when this 'wet' image is included. 
An independent test of the sensitivity of PEST-Noah to the choice of PBMR images was also conducted. PEST-Noah calibrations were performed for the early part of the M90 period using only the first 2 or 3 PBMR images, then evaluating Noah over the remainder of the period with the optimized soil texture as input. The RMSE in simulated soil moisture using this approach are plotted alongside the dependent results in Fig. 7, and are below 2 percent and similar to those from calibrating and evaluating the whole M90 period. This suggests that on very short temporal scales, PEST-Noah could be used with a few images early in the period to calibrate and estimate soil texture, which could then be used to improve simulations going forward without requiring additional images. This type of approach mimics that of an operational and data-limited approach such as that of the ARMS project.

Overall, these results demonstrate that the majority of the improvement using PEST comes from calibrating the overall magnitude and dynamic range of soil moisture by adjusting the sand and clay contents. Also, PEST-Noah significantly reduces errors in simulated soil moisture regardless of the number and which images used. However, the calibration is most accurate when you include more than two images in the calibration process, or at least one or two images that capture and represent the observed range of soil moisture during a drying cycle.

\section{c. 2003 Calibration Experiments}

The development of the delta index allows us to test the PEST-Noah approach using active radar imagery. RADARSAT-1 images were acquired over the WGEW during July, August, and September 2003 that cover a larger temporal and spatial extent than the PBMR images during the M90 period (Fig. 8). As described earlier, the Delta Index data had to be aggregated from 40 to 210 and 280 meter resolution to reduce the impact of speckle (amplified by the high rock content of the soils in this region) on the soil moisture retrievals. PEST-Noah was still run with 
precipitation and land cover data at 40 meter resolution, and therefore required experiments to be conducted to confirm the appropriateness of applying 210 and 280 meter resolution data from active radar to that of a 40 meter pixel.

Analyses showed that the maximum differences in observed PBMR soil moisture within a $280 \mathrm{~m}^{2}$ pixel surrounding each Metflux site were less than 2 percent and well within instrument error $( \pm 5$ percent). PEST-Noah was then run individually over $7 \times 7$ points (to match the resolution of the delta index) surrounding the Kendall site during the M90 period using the 40 meter PBMR data to calibrate. Even at the site with the largest precipitation, land cover, and soil moisture gradients (Kendall), the degree of spatial heterogeneity on the scale of $280 \mathrm{~m}^{2}$ does not lead to significant differences in soil properties estimated by PEST-Noah. The remaining sites are even more uniform in nature, which therefore gives confidence to using the 210 and 280 meter delta index for LH and other sites in 40 meter PEST-Noah calibrations.

To cover the extended period between active radar overpasses, PEST-Noah was run from 30 June - 15 September 2003 using the interpolated precipitation and Kendall forcing data as for the 2003 evaluations described previously. For the Kendall site, PEST-Noah converged on a solution of 100 percent sandy soil for both the 210 and 280 meter images (compared with 89 percent sand; 11 percent clay in M90). At LH, the optimized values for sand, clay, and silt were 28,72 , and 0 percent using 210 meter data, and 20,45 , and 35 percent using 280 meter data (compared with 99 percent sand in M90).

Figure 9a shows that results from Kendall are comparable to the in-situ soil moisture observations, and although this calibration suggests a slightly sandier soil than $M 90$, the differences in soil moisture and hydraulic properties are negligible as discussed in Section 3 a. Following the discussion in Section 3b, the differences in the M90 and 2003 period calibrations 
are primarily due to the lower magnitude range of soil moisture captured by the delta index $(0.153 \mathrm{max}, 0.032 \mathrm{~min})$ compared to the $\operatorname{PBMR}(0.169 \mathrm{max}, 0.075 \mathrm{~min})$. That the first image coincides with a rainfall event means the soil type is less relevant or sensitive to calibration on this date, and actually reflects the need to dry out to match the very low soil moistures given in the next two images.

The PEST-Noah results for LH (Fig. 9b) suggest considerable differences in calibrationsusing the delta index compared with observations and the PBMR calibrations, with a much more clayey soil and higher soil moisture throughout the period. Closer inspection of the in-situ observations of soil moisture over the period shows a comparable range to Kendall. However, the first delta index image (at both 210 and 280 meters) gives a rather wet soil moisture estimate compared to observations, while the latter 2 images are relatively dry and alone would suggest a sandy soil as in previous calibrations. In order to match the high moisture content of the first image, PEST-Noah is forced to simulate a high clay content which has a higher holding capacity and strength:

The first radar overpass is more than 4 days after the last significant rainfall, which means the soil has had significant time to dry out particularly for this region. In fact, studies have shown that the typical response time to rainfall and complete drydown occurs within 2-3 days (or less, depending on ground cover) in WGEW due to the shallow moisture reservoir and high bare soil evaporation rates (Shamir et al. 2005; Kurc and Small 2004). That previous studies, M90 observations (PBMR and in-situ), and in-situ observations all depict a much more rapidly drying soil at the site suggests that the delta index data may not be accurate on this date.

High frequency (active) microwave retrievals are difficult to obtain in regions with high rock content due to increased backscatter and a weaker relationship with soil moisture (Jackson 
1992) even when aggregated to 280 meter resolution, and thus remains an issue. Clearly, if there were more images available, particularly during and immediately following rainfall events, PEST-Noah would be able to perform better as for the M90 case. Houser et al. (1998) made similar recommendations for data assimilation in this region, suggesting that soil moisture observations are required at minimum once every storm event. For the 2003 experiments, it is likely a combination of insufficient temporal sampling and the limited spatial resolution of active remote sensing (through the signal-to-noise ratio) in the soil moisture retrieval process that resulted in poor calibration at $\mathrm{LH}$.

\section{Discussion}

As detailed point or regional surface characteristics are not always available, it is useful to examine the calibration technique at lower spatial resolution. Figure 10 shows simulated soil moisture from default (FAO) Noah and PEST-Noah simulations compared with the PBMR data for the entire PBMR domain on DOY 221. In effect, PEST-Noah is minimizing the mean error in simulated versus observed soil moisture across this region. The last PBMR date was ehosen because it represents the cumulative effect of calibrated parameters on improving soil moisture throughout the M90 period, lowering both RMSE and bias from $\sim 10$ to 3 percent. While there is only one set of optimized soil texture and hydraulic parameters estimated for the entire domain (92 percent sand), the significant improvements indicate that on watershed scales with coarser inputs the calibration process can still successful and potentially useful for deriving meaningful soils data.

Overall, PEST-Noah is able to identify the dominating soil texture and hydraulic properties of the WGEW. It is also important to emphasize that the calibration approach was designed to focus on calibrating a consistent set of hydraulic parameters that would retain the physical 
characteristics of the region in question. Sophisticated techniques have been successful in calibrating complex models, but yield 'effective' parameters that have lost physical meaning. This practice is troubling for the future development and utilization of complex LSMs with respect to the applicability of new and improved parameter data that are likely to be available from remote sensing techniques. As LSMs become increasingly complex, the ability to retain physically meaningful and measurable parameters needs to be addressed in parallel, in a manner similar to this study.

However, it is accepted that some of the errors in model physics, forcing, and parameterizations are accounted for in PEST-Noah calibrations as well, and should be addressed (Scott et al. 2000). While the approach taken here is rather simple compared to complex data assimilation or multi-objective parameter estimation techniques, it is easier to identify errors in the model. One deficiency in the Noah model was identified, where the bare soil evaporation factor should be adjusted (lowered) to allow for greater evaporation rates and soil drying for semi-arid regions with sparse vegetation. The original value, when combined with FAO, STATSGO, and SSURGO parameters in the default simulations led to soils that were consistently too wet for this region (as shown in the results).

It has been noted in numerous studies of the WGEW that there is an unusually high rock fragment content of the upper soil layers (and is not typically accounted for in categorical lookup tables or PTFs). The unique soil type estimated by PEST-Noah at the Metflux sites is a primarily sandy soil that is slightly less porous and more conductive than that observed. In fact, this may be an attempt to indirectly account for the high rock content in Noah by adjusting the parameters to match that of a rocky, yet sandy, soil (i.e. less pore space and increasing flow paths in the soil 
volume). A simple formulation to account for rock content in calculating hydraulic parameters is currently being implemented into Noah to test the sensitivity of the calibrations.

These issues demonstrates the potential for remote sensing data to also offer information on model errors and biases (although small in this case), and advanced techniques such as those offered by Bach and Mauser (2003) and Ines and Droogers (2002) to find and quantify systematic errors in LSM physics. In particular, the recent and ongoing work of Amramowitz et al. (2006) and the Model Parameter Estimation Experiment (MOPEX; Duan et al. 2006) are promising new avenues of research that are working to determine the applicability of studies such as this one to be applied to other LSMs and locations.

\section{Conclusions}

This paper has examined a straightforward method of using microwave remote sensing of near-surface soil moisture to calibrate an offline land surface model, and in the process infer soil texture and hydraulic properties at high spatial resolutions. This approach expands and improves upon a wide body of previous work by incorporating pedotransfer functions into the LSM to ensure consistent and physically meaningful soil parameters, and by addressing the temporal sampling of remote sensing imagery needed for successful calibration. As a testbed for the ARMS project, this research was able to retrieve soil texture and property estimates that correspond well with observed soils over the WGEW. Once estimated for this region, these parameters were also used to simulate soil moisture over seasonal time scales with a great deal of accuracy compared to simulations with default soils and soil properties based on lookup tables.

Specific results of this study include the following:

1) Limited microwave retrievals of near-surface soil moisture can be used to calibrate a LSM to within $.02 \mathrm{~m}^{3} \mathrm{~m}^{-3}$ accuracy at high temporal and spatial resolutions. 
2) Optimizing soil hydraulic properties using PTFs gives better and more physically meaningful results than a one-at-a-time parameter estimation approach.

3) Errors in the calibration process are minimized when there are at least 3 images included that represent the typical range of moisture exhibited by the soil type during a drydown period.

4) Independent tests indicate that this methodlogy can be successful in calibrating LSMs over seasonal and longer timescales for use in specialized prediction systems.

Overall, these results suggest that ARMS could be applied at remote locations to simulate soil moisture in a semi-operational context with limited remote sensing inputs. Simulations that expand the 8 Metflux sites tested here to the full WGEW at 40m resolution of PEST-Noah are ongoing, from which fully distributed maps of soil texture and hydraulic properties will be produced. Alternatively, one could use the PEST-Noah approach after stratifying the watershed using high resolution soils, land cover, or similar data to further examine the spatial distribution of soil properties. Distributed soil property information can then be compared with existing soils maps and the approach repeated and applied to other LSMs and regions.

Finally, the ability of active remote sensing and the delta index technique to retrieve soil moisture on less than watershed scales needs to be investigated further before incorporated in an ARMS-type of approach. While results here have shown that 3 images are sufficient to calibrate and obtain soils information, the soil moisture estimates must be accurate (within $\sim 3-5$ percent) and capture a typical dynamic range of soil moisture for the region in question. The spatial resolution of currently orbiting active remote sensing, determined in part by the signal-to-noise ratio of the measurement, may be a limiting issue for this application. Also, the accuracy of soil moisture retrieval from active remote sensing through approaches like the delta index or other 
retrieval methods (e.g. Alvarez-Mozos et al., 2005) needs further investigation before it can be incorporated with confidence. Future work on the ARMS project will include testing the methodology and evaluating the delta index at cold land, high relief, and highly coupled regions of the U.S., where the calibration process should yield new insight [about?] the images and accuracy required and influence of model physics for diverse surface conditions.

\section{Acknowledgments}

This work was supported by the Army Remote Moisture System project (Grant \#?). Special thanks go to Sujay Kumar and the LIS support team at NASA-GSFC. 


\section{REFERENCES}

Abramowitz, G., Gupta, H., Pitman, A., Wang, Y., Leuning, R., Cleugh, H., \& Hsu, K.-L. (2006). Neural Error Regression Diagnosis (NERD): A Tool for Model Bias Identification and Prognostic Data Assimilation. J. Hydrometeorol., 7, 160-177.

Ahuja, L. R., O. Wendroth, and D. R. Nielsen (1993). Relationship between initial drainage of surface soil and average profile saturated conductivity. Soil Sci. Soc. Amer. J., 57, 19-25.

Alvarez-Mozos, J., J. Casali, M. Gonzalez-Audicana, and N. E. C. Verhoest (2005). Correlation between Ground Measured Soil Moisture and RADARSAT-1 derived Backscattering Coefficient over an Agricultural Catchment of Navarre (North of Spain). Biosystems Engineering, 92, 119-133.

Bach, H. and W. Mauser (2003). Methods and Examples for Remote Sensing Data Assimilation in Land Surface Process Modeling. IEEE Trans. Geosci. Rem. Sens., 41, 1629-1637.

Berbery, E. H., Y. Luo, K. E. Mitchell, and A. K Betts (2003). Eta model estimated land surface processes and the hydrologic cycle of the Mississippi basin. J. Geophys. Res., 108,8852 .

Betts, A. K. (2000). Idealized model for equilibrium boundary layer over land. $J$. Hydrometeor., 1, 507-523.

Betts, A. K., J. H. Ball, M. Bosilovich, P. Viterbo, Y. Zhang, and W. B. Rossow (2003). Intercomparison of water and energy budgets for five Mississippi subbasins between ECMWF reanalysis (ERA-40) and NASA Data Assimilation Office fvGCM for 1990-1999. J. Geophys. Res., 108, 8618.

Braun, F. J. and G. Schadler (2005). Comparison of Soil Hydraulic Parameterizations for Mesoscale Meteorological Models. J. Appl. Meterol., 44, 1116.

Burke, E. J., R. J. Gurney, L. P. Simmonds, and T. J. Jackson (1997). Calibrating a soil water and energy budget model with remotely sensed data to obtain quantitative information about the soil. Water Resour. Res., 33, 1689-1697.

Burke, E. J., R. J. Gurney, L. P. Simmonds, and P. E. O'Neill (1998). Using a modeling approach to predict soil hydraulic properties from passive microwave measurements. IEEE Transactions on Geoscience and Remote Sensing, 36, 454-462.

Camillo, P. J., P. E. O’Neill, and R. J. Gurney (1986). Estimating Soil Hydraulic Parameters Using Passive Microwave Data. IEEE Trans. Geosci. Rem. Sens., GE-24, 930-936.

Carlson, T. N., R. R. Gillies, and T. J. Shmugge (1995). An interpretation of methodologies for indirect measurement of soil water content. Agric. Forest. Meteorol., 77, 191-205. 
Chen, F., K. Mitchell, J. Schaake, Y. Xue, H. Pan, V. Koren, Y. Duan, M. Ek, and A. Betts (1996). Modeling of land-surface evaporation by four schemes and comparison with FIFE observations. J. Geophys. Res., 101, 7251-7268.

Cuenca, R. H., M. Ek, and L. Mahrt (1996). Impact of soil water property parameterization on atmospheric boundary layer simulation. J. Geophys. Res. Atmos., 101, 7269-7277.

Doherty, J. (2004). PEST: Model Independent Parameter Estimation. Fifth edition of user manual. Watermark Numerical Computing, Brisbane, Australia.

Duan, Q., J. Schaake, V. Andreassian, S. Franks, G. Goteti, H. V. Gupta, Y. M. Gusev, F. Habets, A. Hall, L. Hay, T. Hogue, M. Huang, G. Leavesley, X. Liang, O. N. Nasnonova, J. Noilhan, L. Oudin, S. Sorooshian, T. Wagener, E. F. Wood (2006). Model Parameter Estimation Experiment (MOPEX): An overview of science strategy and major results from the second and third workshops. J. Hydrology, 320, 3-17.

Ek, M. and R. H. Cuenca (1994). Variation in soil parameters: Implications for modeling surface fluxes and atmospheric boundary-layer development. Bound.-Layer Meteorol., 70, 369-383.

Ek., M. B., and A. A. M. Holtslag (2003). Influence of Soil Moisture on Boundary Layer Cloud Development. J. Hydrometeorol., 5, 86-99.

Entekhabi, D. et al. (1999). An Agenda for Land Surface Hydrology Research and a Call for the Second International Hydrological Decade. Bull. Amer. Meteor. Soc., 79, 27432746.

FAO-UNESCO, 1981, Soil Map of the World, Ten Volumes, Food and Agriculture Organization, Rome.

Feddes, R. A., M. Menenti, P. Kabat, W. G. M. Bastiaanssen (1993). Is Large-Scale Inverse Modelling of Unsaturated Flow with Areal Average Evaporation and Surface Soil Moisture as Estimated from Remote Sensing Feasible? J. Hydrology, 143, 125-152.

Findell, K. L. and E. A. B. Eltahir (2003a,b). Atmospheric Controls on Soil

Moisture-Boundary Layer Interactions. Part I: Framework Development and Part II: Feedbacks within the Continental United States. J. Hydrometeorol., 4, 552-583.

Garcia, M., C. D. Peters-Lidard, and D. C. Goodrich (2006). Spatial interpolation of precipitation in a dense gauge network for monsoon storm events in the southwestern U.S. Water Resour. Res., under review.

Gupta, H.V., L. A. Bastidas, L., S. Sorooshian, W.J. Shuttleworth, and Z.L. Yang (1999). Parameter Estimation of a Land Surface Scheme using Multi-Criteria Methods. J. Geophys. Res., 104, 19,491-19,504.

Gutmann, E. D. and E. E. Small (2005). The effect of soil hydraulic properties vs. soil texture in 
land surface models. Geophys. Res. Letters, 32, L02402.

Hansen, M. C., R. S. Defries, J. R. G. Townshend, and R. Sohlberg (2000). Global land cover classification at $1 \mathrm{~km}$ spatial resolution using a classification tree approach. Int. Jour. Remote Sens., 21, 1331-1364.

Hess, R. (2001). Assimilation of screen-level observations by variational soil moisture analyses. Meteorol. Atmos. Phys., 77, 145-154.

Higgins W., D. Ahijevych, J. Amador, A. Barros, E. H. Berbery, E. Caetano, R. Carbone, P. Ciesielski, R. Cifelli, M. Cortez-Vazquez, A. Douglas, M. Douglas , G. Emmanuel, C. Fairall , D. Gochis, D. Gutzler, T. Jackson, R. Johnson, C. King, T. Lang, M. I. Lee, D. Lettenmaier, R. Lobato, V. Magana, J. Meiten, K. Mo, S. Nesbitt, F. Ocampo-Torres, E. Pytlak, P. Rogers, S. Rutledge, J. Schemm, S. Schubert, A. White, C. Williams, A. Wood, R. Zamora, C. D. Zhang (2006). The NAME 2004 field campaign and modelling strategy. Bull. Amer. Meteorol. Soc., 87, 79-94.

Hogue, T. S., L. Bastidas, H. Gupta, S. Sorooshian, K. Mitchell, and W.

Emmerich (2005). Evaluation and Transferability of the Noah Land Surface Model in Semiarid Environments. J. Hydrometeorol., 6, 68-84.

Hollenbeck, K.J., T.J. Schmugge, G.M. Hornberger, and J.R. Wang (1996). Identifying soil hydraulic heterogeneity by detection of relative change in passive microwave remote sensing observations, Water Resour. Res., 32, 139-148.

Houser, P. R., W. J. Shuttleworth, J. S. Famiglietti, H. V. Gupta, K. H. Syed, and D. C. Goodrich (1998). Integration of soil moisture remote sensing and hydrologic modeling using data assimilation. Water Resour. Res., 34, 3405-3420.

Ines, A. V. M. and P. Droogers (2002). Inverse Modelling in Estimation Soil Hydraulic Functions: A Genetic Algorithm Approach. Hydrology and Earth System Sciences, 6, 4965.

Jacobs, C. M. J., and H. A. R. Debruin (1992). The sensitivity of regional transpiration to landsurface characteristics - significance of feedback. J. Climate, 5, 683-698.

Jackson, T. J. (1992). Rock fraction effects on the interpretation of microwave emission from soils, IEEE Trans. Geosci. Rem. Sens., 30, 610-616.

Koster, R. D. ete al. (2004). Regions of Strong Coupling Between Soil Moisture and Precipitation. Science, 305, 1138-1140.

Kurc, S. A., and E. E. Small (2004). Dynamics of evapotranspiration in semiarid grassland and shrubland ecosystem during the summer monsoon season, central New Mexico. Water Resour. Res., 40, W09305. 
Kustas, W.P., D. C. Goodrich, M. S. Moran, S. A. Amer, L. B. Bach, J. H. Blanford, A. Chehbouni, H. Claassen, W. E. Clements, P. C. Doraiswamy, P. Dubois, T. R. Clarke, C. S. T. Daughtry, D. I. Gellman, T. A. Grant, L. E. Hipps, A. R. Huete, K. S. Humes, T. J. Jackson, T. O. Keefer, W. D. Nichols, R. Parry, E. M. Perry, R. T. Pinker, P. J. Pinter, Jr., J. Qi, A. C. Riggs, T. J. Schumgge, A. M. Shutko, D. I. Stannard, E. Swiatek, J. D. van Leeuwen, J. van Zyl, A. Vidal, J. Washburne, and M. A. Weltz (1991). An Interdisciplinary Field Study of the Energy and Water Fluxes in the Atmosphere-Biosphere System over the Semiarid Rangelands: Description and Some Preliminary Results. Bull. Amer. Meteor. Soc., 72, 1683-1705.

Liu, Y., L. A. Bastidas, H. V. Gupta, and S. Sorooshian (2003). Impacts of a Parameterization Deficiency on Offline and Coupled Land Surface Model Simulations. J. Hydrometeorol., 4, 901-914.

Liu, Y., H. V. Gupta, S. Sorooshian, L. A. Bastidas, and W. J. Shuttleworth (2004). Exploring Parameter Sensitivities of the Land Surface Using a Locally Coupled Land-Atmosphere Model. J. Geophys. Res., 109, $21101-21114$.

Liu, Y., H. V. Gupta, S. Sorooshian, L. A. Bastidas, and W. J. Shuttleworth (2005). Constraining Land Surface and Atmospheric Parameters of a Locally Coupled Model Using Observational Data. J. Hydrometeorol., 6, 156-172.

Mattikalli, N. M., E. T. Engman, L. R. Ahuja, and T. J. Jackson (1998). Microwave Remote Sensing of Soil Moisture for Estimation of Profile Soil Property. Int. J. Remote Sensing, 19, 1751-1767.

Mocko, D. M., C. D. Peters-Lidard, M. A. Tischler, Y. Wu, M. E. Garcia, and J. A. Santanello, Jr. (2006). The Relative Roles of Soil, Land Cover, and Precipitation Uncertainty for Watershed-scale Soil Moisture Prediction in a Semi-arid Environment. Water Resour. Res., in prep.

Mohanty, B. P., P. J. Shouse, D. A. Miller, and M. T. van Genuchten (2002). Soil property database: Southern Great Plains 1997 Hydrology Experiment. Water Resour. Res., 38, \#1047.

Moran, M. S., C. D. Peters-Lidard, J. M. Watts, and S. McElroy (2004). Estimating soil moisture at the watershed scale with satellite-based radar and land surface models. Can. J. Remote Sens., 30, 805-826.

Pitman, A. J. (2003). The Evolution of, and Revolution in, Land Surface Schemes Designed for Climate Models. Int. J. Climatol., 23, 479-510.

Rawls, W. J., D. L. Brakensiek, and K. E. Saxton (1982). Estimation of Soil Water Properties. Trans. of the A.S.A.E., 1316-1320.

Rhodin, A., F. Kucharski, U. Callies, D. P. Eppel, and W. Wergen (1999). 
Variational analysis of effective soil moisture from screen-level atmospheric parameters: Application to a short-range weather forecast model. $Q$. J. R. Meteorol. Soc., 125, $2427-$ 2448.

Richards, L. A. (1931). Capillary conduction of liquids through porous mediums. J. Appl. Phys., 1, 318-333.

Robock, A., L. F. Luo, E. F. Wood, F. H. Wen, K. E. Mitchell, P. R. Houser, J. C. Schaake, D. Lohmann, B. Cosgrove, J. Sheffield, Q. Y. Duan, R. W. Higgins, R. T. Pinker, J. D. Tarpley, J. B. Basara, and K. C. Crawford (2003). Evaluation of the North American Land Data Assimilation System over the southern Great Plains during the warm season. J. Geophys. Res., 108, No. 8846.

Santanello, J. A. and T. N. Carlson (2001). Mesoscale Simulation of Rapid Soil Drying and its Implications for Predicting Daytime Temperature. J. Hydrometeorol., 2, 71-88.

Schaap, M. G., F. J. Leij, and M. T. van Genuchten (1998). Neural network analysis for hierarchical prediction for soil hydraulic properties. Soil Sci. Soc. Am. J., 62, 847-855.

Schaap, M. G., and P. J. Shouse (2004). Hydraulic data were collected and analyzed by Marcel G. Schaap, Univ. California at Riverside (SAHRA Science and Technology Center, NSF EAR-9876800) and Peter J. Shouse, GEBJ Salinity Laboratory (USDA-ARS), Riverside.

Schmugge, T., Jackson, T. J., Kustas, W. P., Roberts, R., Parry, R., Goodrich, D. C., Amer, S. A., \& Weltz, M. A. (1994). Push broom microwave radiometer observations of surface soil moisture in Monsoon '90. Water Resour. Res., 30, 1321-1327.

Schmugge, T. (1998). Applications of passive microwave observations of surface soil moisture. J. Hydrology, 213, 188-197.

Scott, R. L., W. J. Shuttleworth, T. O. Keefer, and A. W. Warrick (2000). Modeling multiyear observations of soil moisture recharge in the semiarid American Southwest. Water Resour. Res., 36, 2233-2247.

Shamir, E., Imam, B., Gupta, H. V., and Sorooshian, S. (2005). Application of temporal streamflow descriptors in hydrologic model parameter estimation. Water Resour. Res., 41, W06021.

Sobieraj, J. A., H. Elsenbeer, and R. A. Vertessy (2001). Pedotransfer functions for estimating saturated hydraulic conductivity: implications for modeling storms flow generation. $J$. Hydrology, 251, 202-220.

Soet, M., and J. N. M. Stricker (2003). Functional behaviour of pedotransfer functions in soil water flow simulation. Hydrol. Proc., 17, 1659-1670.

Sun, W. Y., and M. G. Bosilovich (1996). Planetary boundary layer and surface layer sensitivity 
to land surface parameters. Boundary-Layer Meteorol., 77, 353-378.

Tischler, M., M. Garcia, C. Peters-Lidard, M. S. Moran, S. Miller, D. Thoma, S. Kumar, and J. Geiger (2006). A GIS framework for surface-layer soil moisture estimation combining satellite radar measurements and land surface modeling with soil physical property estimation. Environ. Modeling and Software, in press.

Thoma, D. P., M. S. Moran, R. Bryant, M. Rahman, C. D. Holifield-Collins, S. Skirvin, E. E. Sano, and K. Slocum (2006). Comparison of Four Models to Determine Surface Soil Moisture from C-band Radar Imagery in a Sparsely Vegetated Semiarid Landscape. Water Resour. Res., 42, W01418.

Troen, I. B., and L. Mahrt (1984). A simple model of the atmospheric boundary layer; sensitivity to surface evaporation. Boundary-Layer Meteorol., 37, 129-148.

U.S. Department of Agriculture, Natural Resources Conservation Service, 1994, State Soil Geographic (STATSGO) database for Arizona, http://www.essc.psu.edu/soil info/index.cgi?soil data\&statsgo, Penn State University Earth Systems Science Center, State College, PA.

U.S. Department of Agriculture, Natural Resources Conservation Service, 2002, Soil Survey Geographic (SSURGO) Database for Cochise County, Arizona, Douglas-Tombstone Part, http://www.ncgc.nrcs.usda.gov/branch/ssb/products/ssurgo/, National Cartography and Geospatial Center, Ft. Worth, TX.

Vandegriend, A. A. and P. E. O'Neill (1986). Discrimination of soil hydraulic properties by combined thermal infrared and microwave remote sensing. ESA Proceedings of the 1986 International Geoscience and Remote Sensing Symposium (IGARSS '86) on Remote Sensing: Today's Solutions for Tomorrow's Information Needs, 2, 839-845. 


\section{LIST OF TABLES}

Table 1: Optimized sand, silt, and clay percentages estimated from a) PEST-Noah simulations at the eight Metflux sites compared with b) those observed by Schmugge et al. (1994) and during the NAME (Higgins et al. 2006) in 2004, and associated hydraulic properties computed for each using the PTFs employed in Noah (Cosby et al. 1984).

Table 2: Soil hydraulic parameters used in the Noah model at the a) Kendall and b) Lucky Hills sites derived from default lookup tables based on FAO, STATSGO, and SSURGO classifications and those computed from PEST-Noah estimates of sand, silt, and clay percentages at each site using the PTFs in Noah. For comparison, soil properties estimated by Scott et al. (2000) from a neural network PTF (ROSETTA; Schaap et al. 1998) are shown along with site-specific estimates of hydraulic parameters based on soil samples taken during 2002 (Schaap and Shouse 2004) and NAME (Higgins et al. 2006) in 2004. 


\section{LIST OF FIGURES}

Figure 1: The Walnut Gulch Experimental Watershed in southeastern Arizona (outlined in black) covers $148 \mathrm{~km}^{2}$ and is heavily instrumented with meteorological, flux, and rain gauge data. The M90 experiment included 8 Metflux sites ( ${ }^{\circ}$ ) of which Lucky Hills (Site 1) and Kendall (Site 5) were supersites. Overlain are estimates of volumetric soil moisture $\left(\mathrm{m}^{3} \mathrm{~m}^{-3}\right.$ *100) derived from Push Broom Microwave Radiometer measurements on DOY 214.

Figure 2: Soil moisture in the 0-5 cm layer at the a) Kendall and b) Lucky Hills sites during the Monsoon '90 study period from (a) PBMR retrievals (Schmugge et al. 1994) and (A) gravimetric measurements with standard deviations of the 3 measurements made at each site. Also plotted are the 6-hourly precipitation totals during the period at each site as derived from the 84-gauge interpolated dataset over WGEW (Garcia et al. 2006)

Figure 3: Simulated 0-5 cm soil moisture from default and PEST-calibrated Noah simulations for the a) Kendall and b) Lucky Hills sites during the M90 period. Measurements of soil moisture from PBMR and gravimetric sensors on the 6 optimization dates are also shown.

Figure 4: Bias and RMSE in simulated versus observed (PBMR) $0-5 \mathrm{~cm}$ soil moisture during the M90 period using default (FAO; gray) and optimized (PEST; black) soil properties at each Metflux site.

Figure 5: Percentages of sand, silt, and clay estimated by PEST-Noah at the eight Metflux sites compared with in-situ measurements from Schmugge et al. (1994). 
Figure 6: Near-surface soil moisture simulated by Noah using PEST-derived soil properties and default soil parameters (FAO) compared against Vitel probe observations at the a) Kendall and b) Lucky Hills sites during summer 2003.

Figure 7: Errors in simulated versus observed $0-5 \mathrm{~cm}$ soil moisture at the Kendall site for varying a) numbers of PBMR images used in PEST-Noah and b) ranges of soil moisture covered by these images. The lightly shaded points indicate simulations that were calibrated using only the first two and three PBMR images.

Figure 8: Soil moisture $\left(\mathrm{m} 3 \mathrm{~m}^{-3}\right)$ estimated from RADARSAT-1 active microwave measurements over the WGEW on a) 29 July, b) 22 August, and c) 15 September 2003. Backscatter was aggregated from 7 to 280 meters to reduce the effects of speckle and converted to soil moisture using the delta index image differencing technique (Thoma et al. 2006).

Figure 9: Near-surface soil moisture simulated by PEST-Noah using 210 and 280 meter Delta Index as observations at the a) Kendall and b) Lucky Hills sites during summer 2003. Also shown are observations of soil moisture from Vitel probes surrounding each location.

Figure 10: RMSE and bias in simulated versus observed $0-5 \mathrm{~cm}$ soil moisture using a) default (FAO) soils and b) soil properties optimized using PEST-Noah on DOY 221. A single set of parameters were optimized for the entire PBMR domain. 
a)

\begin{tabular}{|c|c|c|c|c|c|c|c|c|}
\hline PEST Site & $\%$ SAND & \% SILT & \% CLAY & $K_{\text {sat }}\left(\mathrm{m} \mathrm{s}^{-1}\right)$ & $K_{\text {sar }}\left(\mathrm{cm} \mathrm{d}^{-1}\right)$ & $\boldsymbol{b}^{\prime}$ & $\theta_{s}\left(\mathrm{~m}^{3} \mathrm{~m}^{-3}\right)$ & $\psi_{\text {sat }}(\mathrm{m})$ \\
\hline $1(\mathrm{LH})$ & 99 & 0 & 1 & $3.01 \times 10^{-5}$ & 260.1 & 3.1 & 0.364 & 0.0383 \\
\hline 2 & 73 & 22 & 5 & $1.20 \times 10^{-5}$ & 103.7 & 3.7 & 0.397 & 0.0839 \\
\hline 3 & 91 & 0 & 9 & $2.27 \times 10^{-5}$ & 196.1 & 4.3 & 0.374 & 0.0487 \\
\hline 4 & 86 & 0 & 13 & $1.91 \times 10^{-5}$ & 165.0 & 4.9 & 0.381 & 0.0567 \\
\hline 5 (Kendall) & 89 & 0 & 11 & $2.12 \times 10^{-5}$ & 183.2 & 4.7 & 0.376 & 0.0518 \\
\hline 6 & 90 & 0 & 10 & $2.19 \times 10^{-5}$ & 189.2 & 4.5 & 0.376 & 0.0502 \\
\hline 7 & 100 & 0 & 0 & $3.12 \times 10^{-5}$ & 269.6 & 2.9 & 0.363 & 0.0372 \\
\hline 8 & 98 & 0 & 2 & $2.91 \times 10^{-5}$ & 251.4 & 3.2 & 0.366 & 0.0395 \\
\hline
\end{tabular}

b)

\begin{tabular}{|c|c|c|c|c|c|c|c|c|}
\hline Observed Site & $\%$ SAND & \% SIILT & \% CLAY & $\boldsymbol{K}_{\text {sat }}\left(\mathrm{m} \mathrm{s}^{-1}\right)$ & $\boldsymbol{K}_{\text {sat }}\left(\mathrm{cm} \mathrm{d}^{-1}\right)$ & $\boldsymbol{b}$ & $\theta_{s}\left(\mathrm{~m}^{3} \mathrm{~m}^{-3}\right)$ & $\boldsymbol{\psi}_{\text {sat }}(\mathrm{m})$ \\
\hline 1 & 66 & 10 & 24 & $9.42 \times 10^{-6}$ & 81.4 & 4.5 & 0.406 & 0.1036 \\
\hline 1 (NAME) & 68 & 21 & 11 & $1.01 \times 10^{-5}$ & 87.2 & 4.7 & 0.400 & 0.0975 \\
\hline 2 & 69 & 11 & 20 & $1.05 \times 10^{-5}$ & 90.7 & 4.7 & 0.402 & 0.0946 \\
\hline 3 & 71 & 9 & 20 & $1.12 \times 10^{-5}$ & 96.8 & 4.3 & 0.399 & 0.0891 \\
\hline 4 & 73 & 5 & 22 & $1.21 \times 10^{-5}$ & 104.5 & 3.7 & 0.397 & 0.0838 \\
\hline 5 & 69 & 11 & 20 & $1.05 \times 10^{-5}$ & 90.7 & 4.7 & 0.402 & 0.0946 \\
\hline 5 (NAME) & 67 & 17 & 16 & $9.76 \times 10^{-6}$ & 84.3 & 5.5 & 0.400 & 0.1000 \\
\hline 6 & 67 & 8 & 25 & $9.76 \times 10^{-6}$ & 84.3 & 4.2 & 0.405 & 0.1005 \\
\hline 7 & 80 & 6 & 14 & $1.54 \times 10^{-5}$ & 133.1 & 3.9 & 0.388 & 0.0679 \\
\hline 8 & 72 & 8 & 20 & $1.16 \times 10^{-5}$ & 100.2 & 4.2 & 0.398 & 0.0864 \\
\hline
\end{tabular}

Table 1: Optimized sand, silt, and clay percentages estimated from a) PEST-Noah simulations at the eight Metflux sites compared with $b$ ) those observed by Schmugge et al. (1994) and during the NAME (Higgins et al. 2006) in 2004, and associated hydraulic properties computed for each using the PTFs employed in Noah (Cosby et al. 1984). 


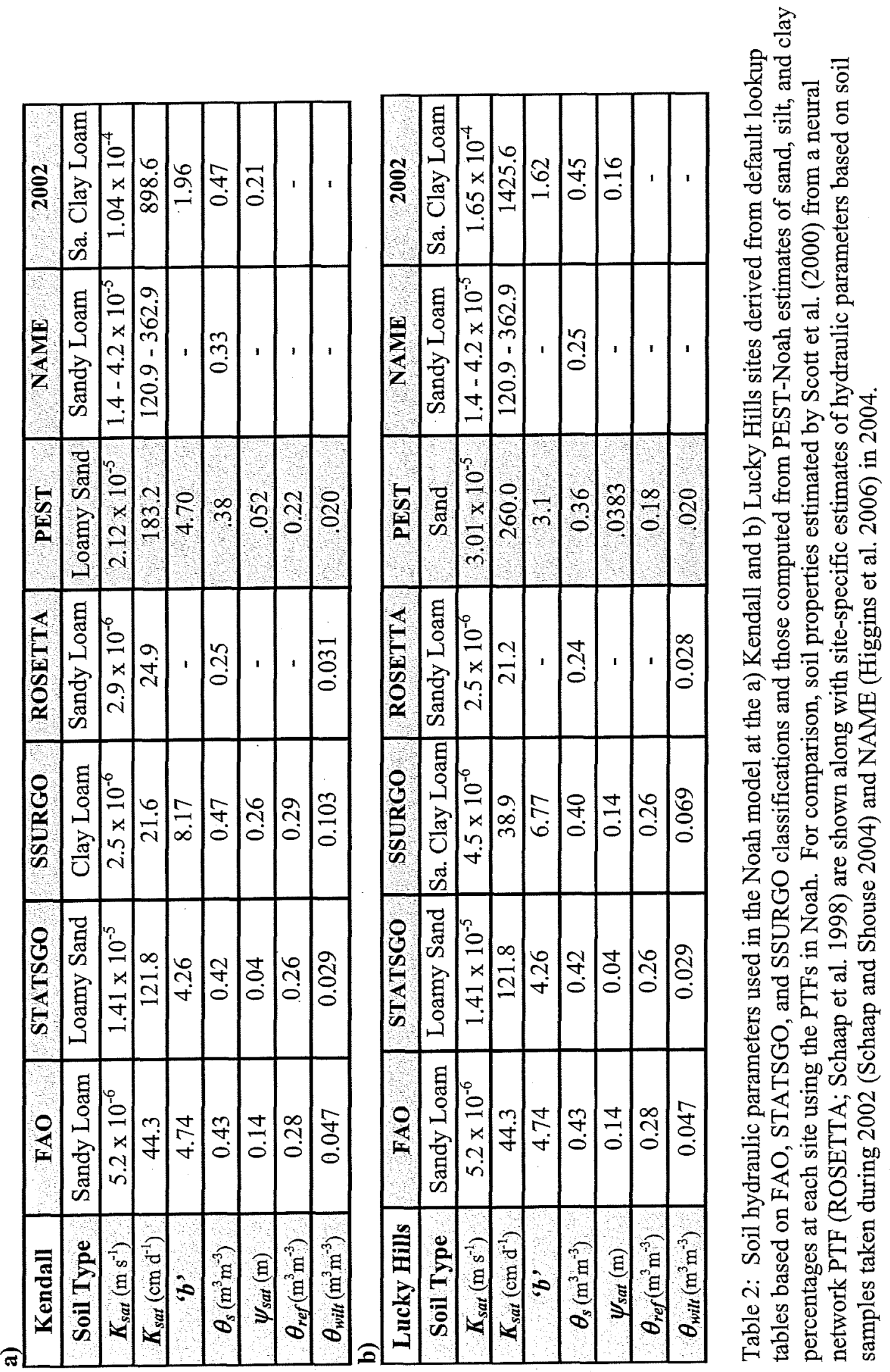




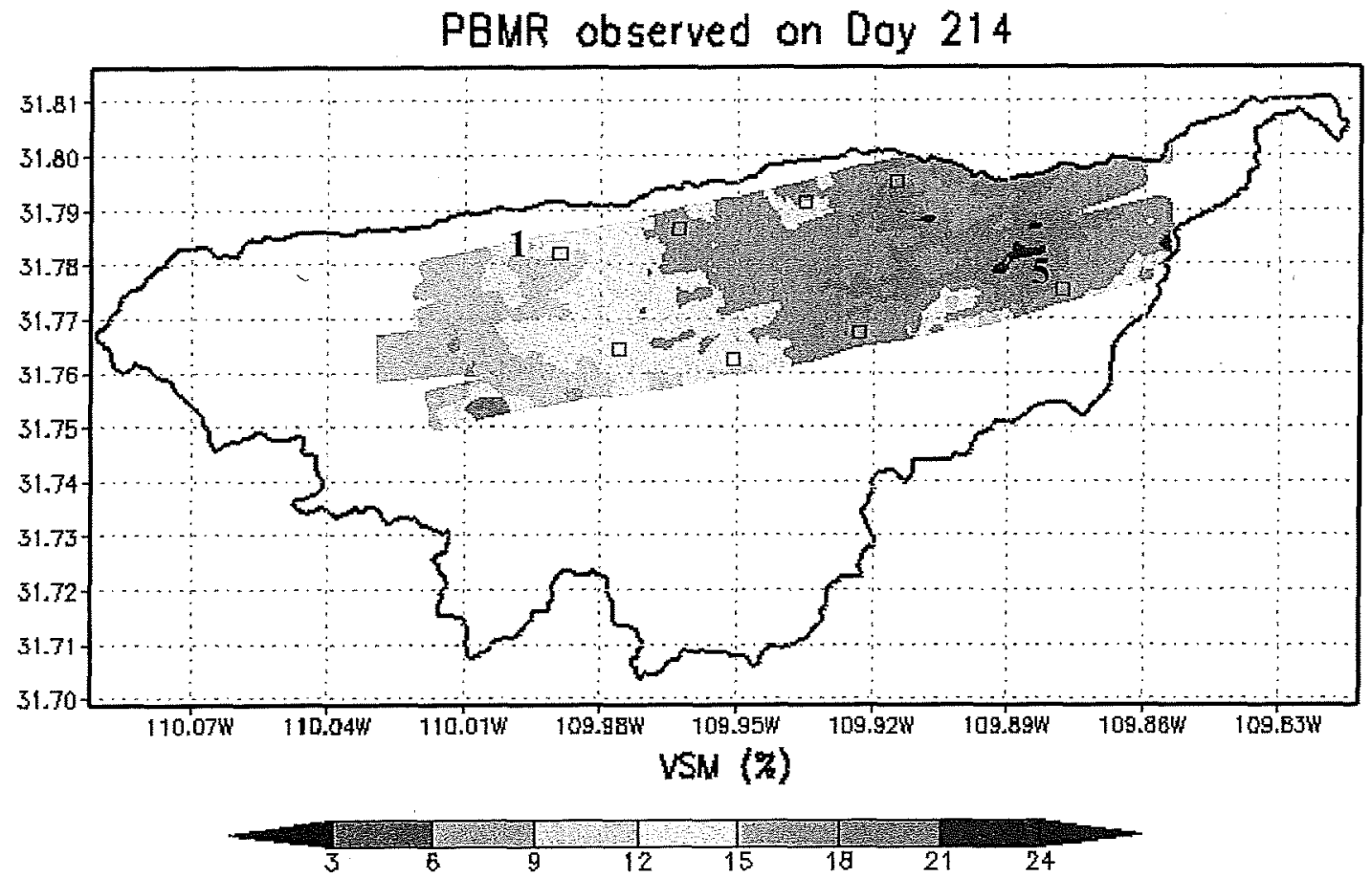

Figure 1: The Walnut Gulch Experimental Watershed in southeastern Arizona (outlined in black) covers $148 \mathrm{~km}^{2}$ and is heavily instrumented with meteorological, flux, and rain gauge data. The M90 experiment included 8 Metflux sites ( ${ }^{a}$ ) of which Lucky Hills (Site 1) and Kendall (Site 5) were supersites. Overlain are estimates of volumetric soil moisture $\left(\mathrm{m}^{3} \mathrm{~m}^{-3} * 100\right)$ derived from Push Broom Microwave Radiometer measurements on DOY 214. 
a)

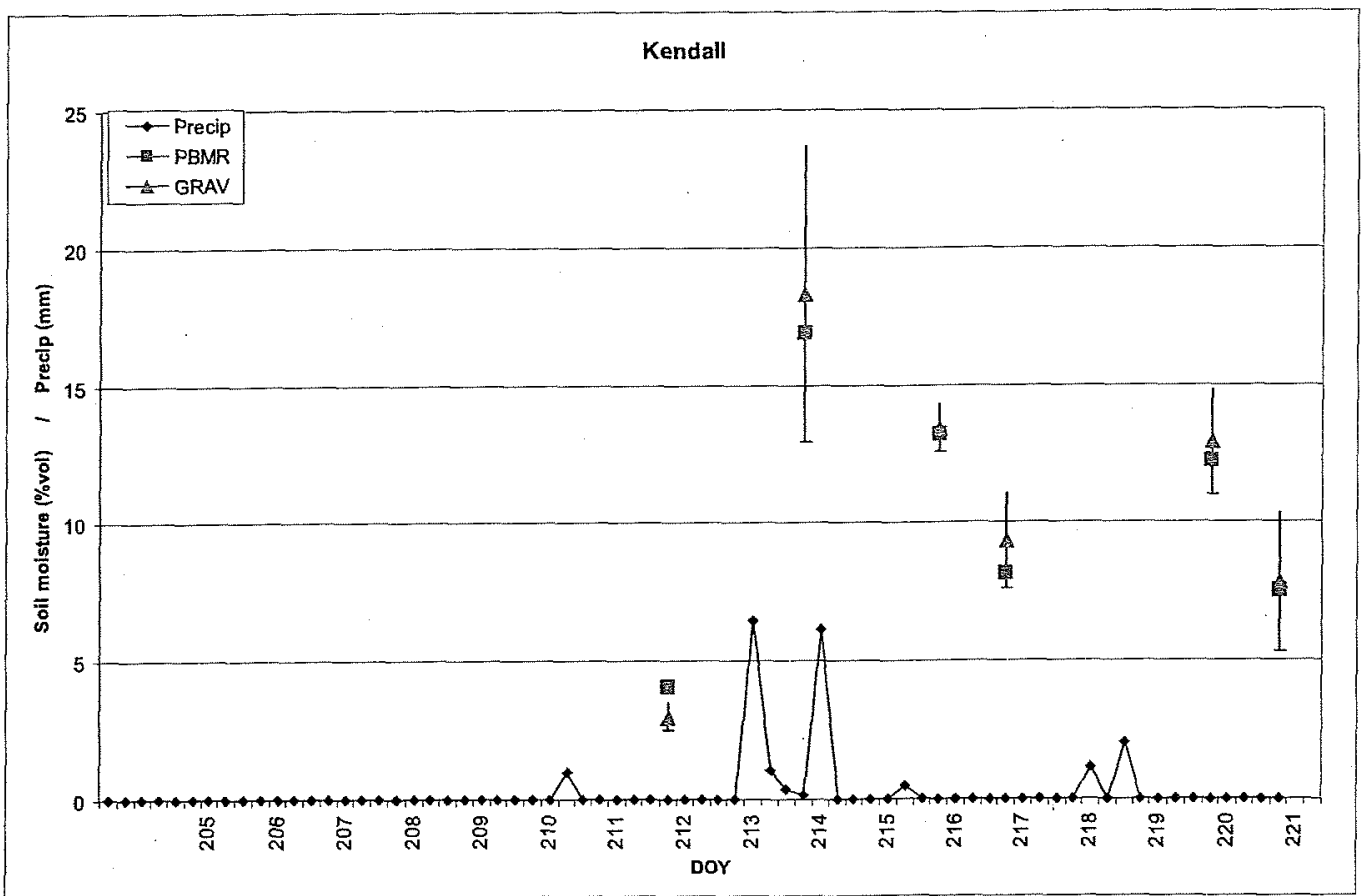

b)

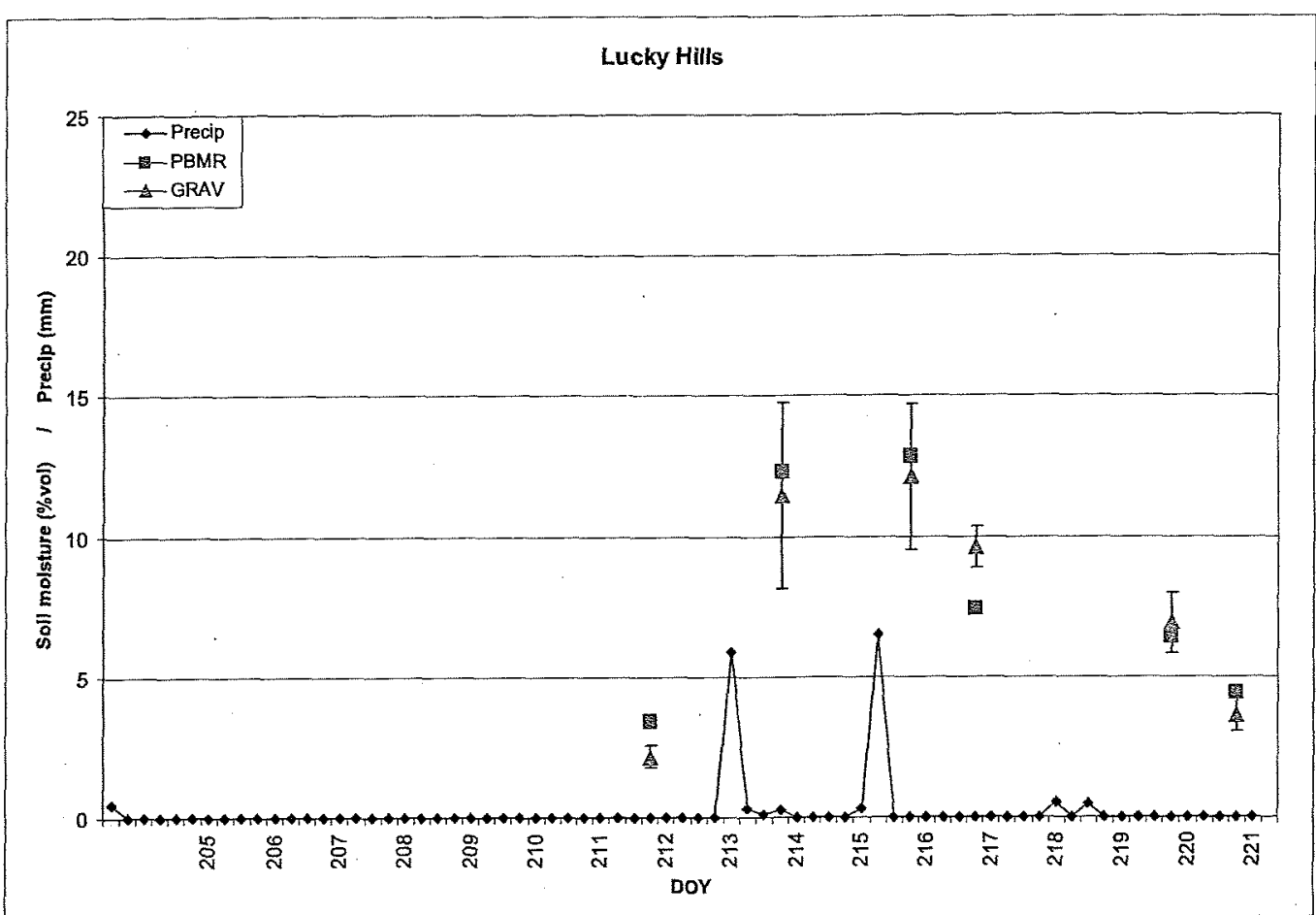

Figure 2: Soil moisture in the 0-5 cm layer at the a) Kendall and b) Lucky Hills sites during the Monsoon '90 study period from ( $\mathbf{m}$ ) PBMR retrievals (Schmugge et al. 1994) and $(\mathbf{\Delta})$ gravimetric measurements with standard deviations of the 3 measurements made at each site. Also plotted are the 6-hourly precipitation totals during the period at each site as derived from the 84-gauge interpolated dataset over WGEW (Garcia et al. 2006) 
a)

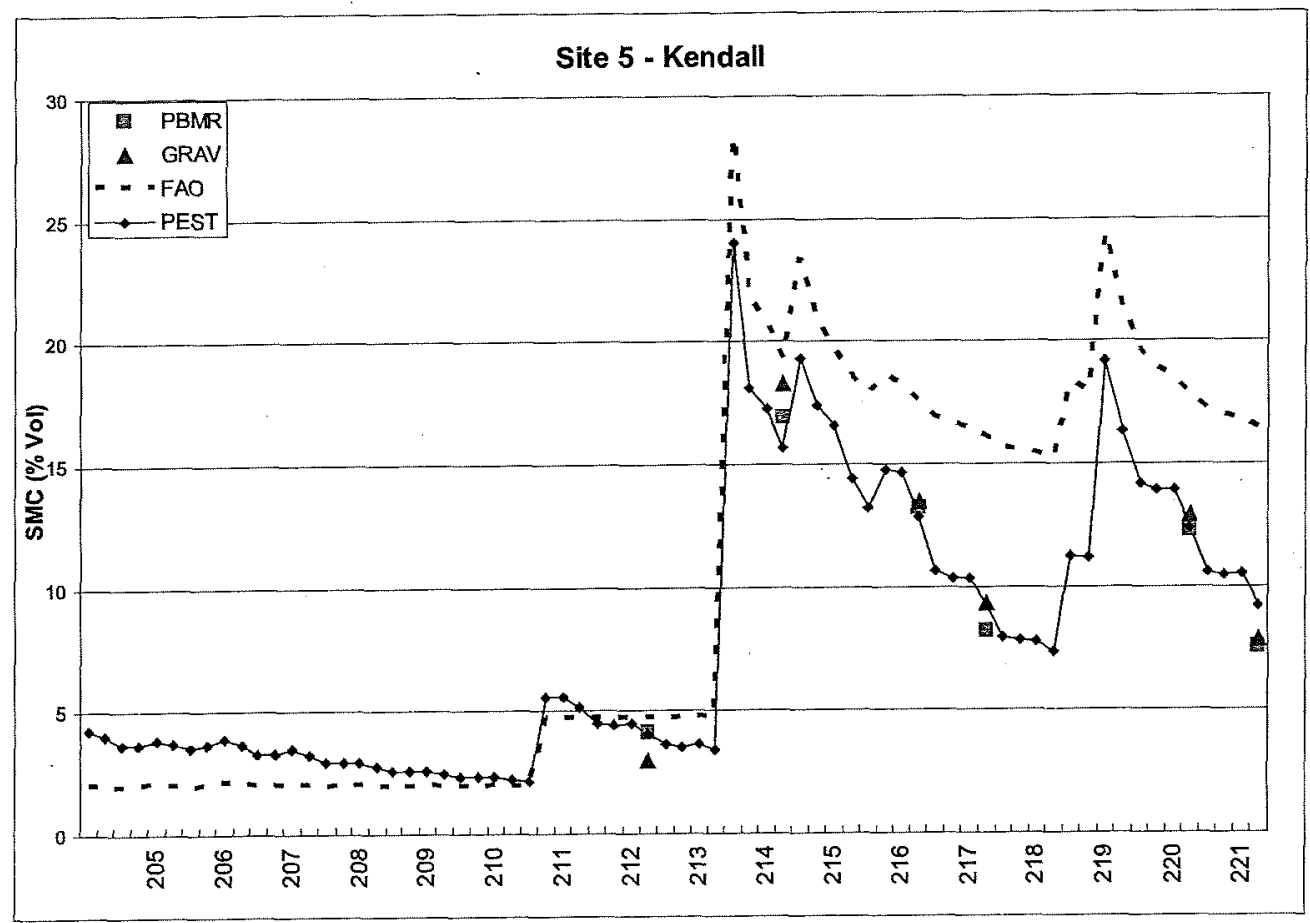

b)

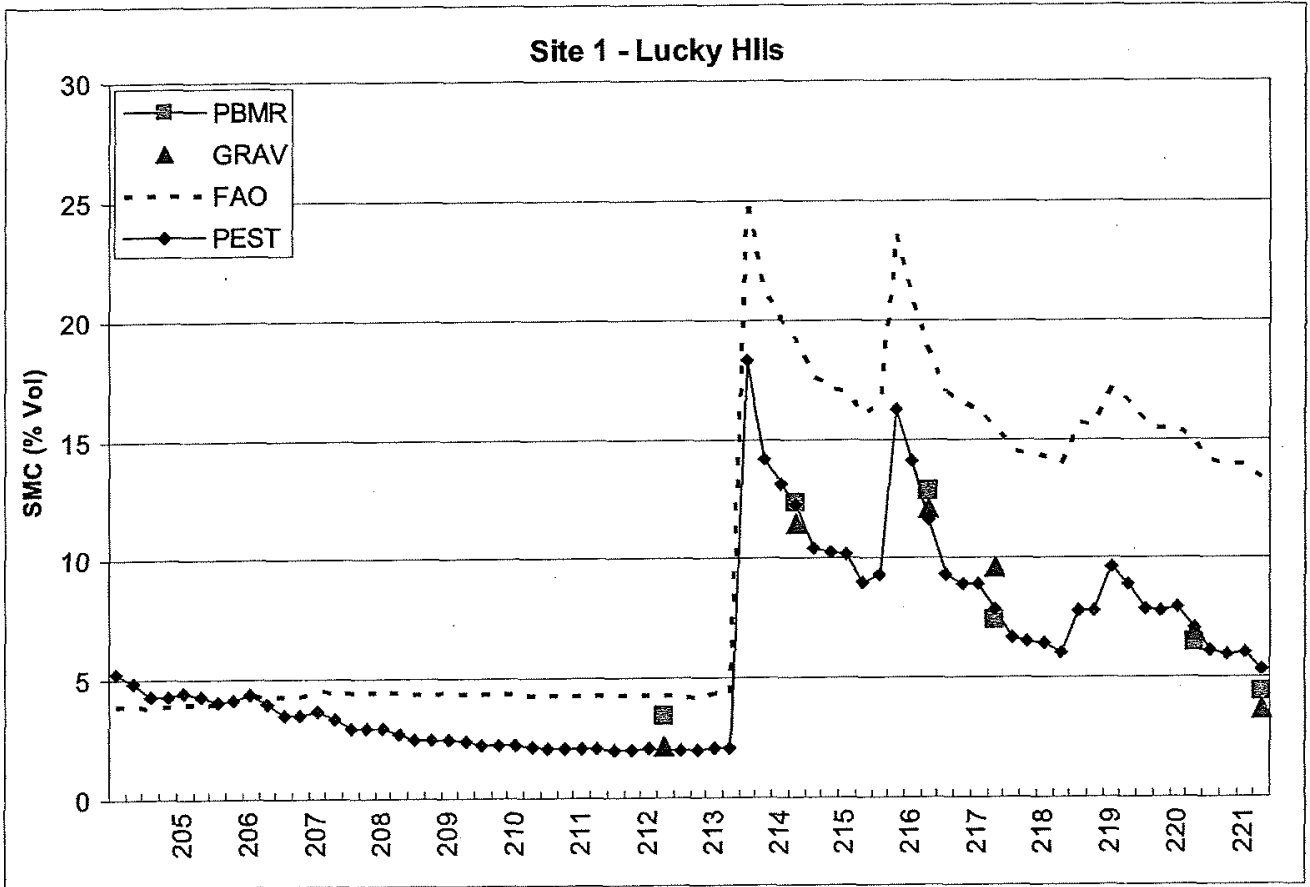

Figure 3: Simulated 0-5 cm soil moisture from default and PEST-calibrated Noah simulations for the a) Kendall and b) Lucky Hills sites during the M90 period. Measurements of soil moisture from PBMR and gravimetric sensors on the 6 optimization dates are also shown. 


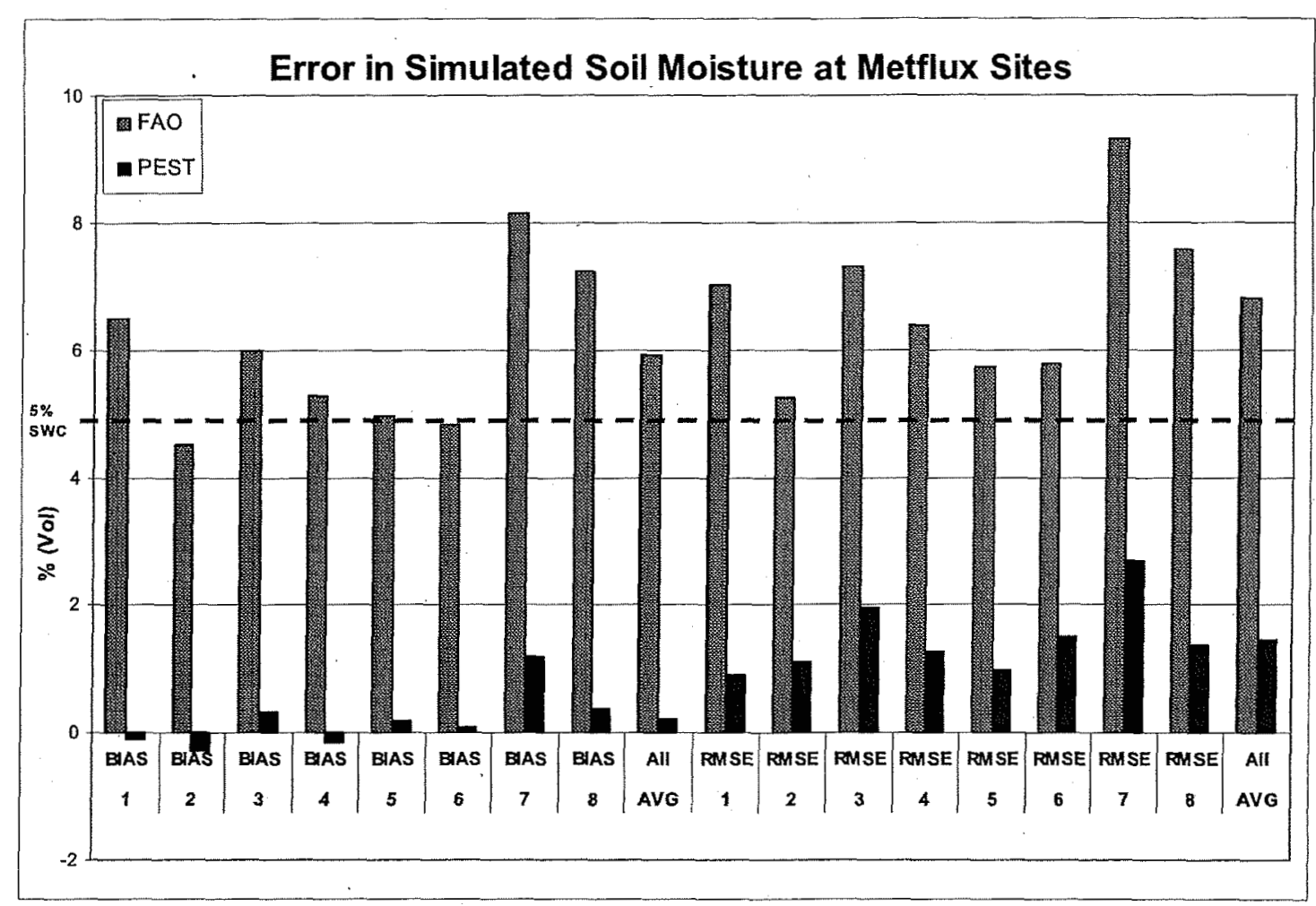

Figure 4: Bias and RMSE in simulated versus observed (PBMR) 0-5 cm soil moisture during the M90 period using default (FAO; gray) and optimized (PEST; black) soil properties at each Metflux site. 


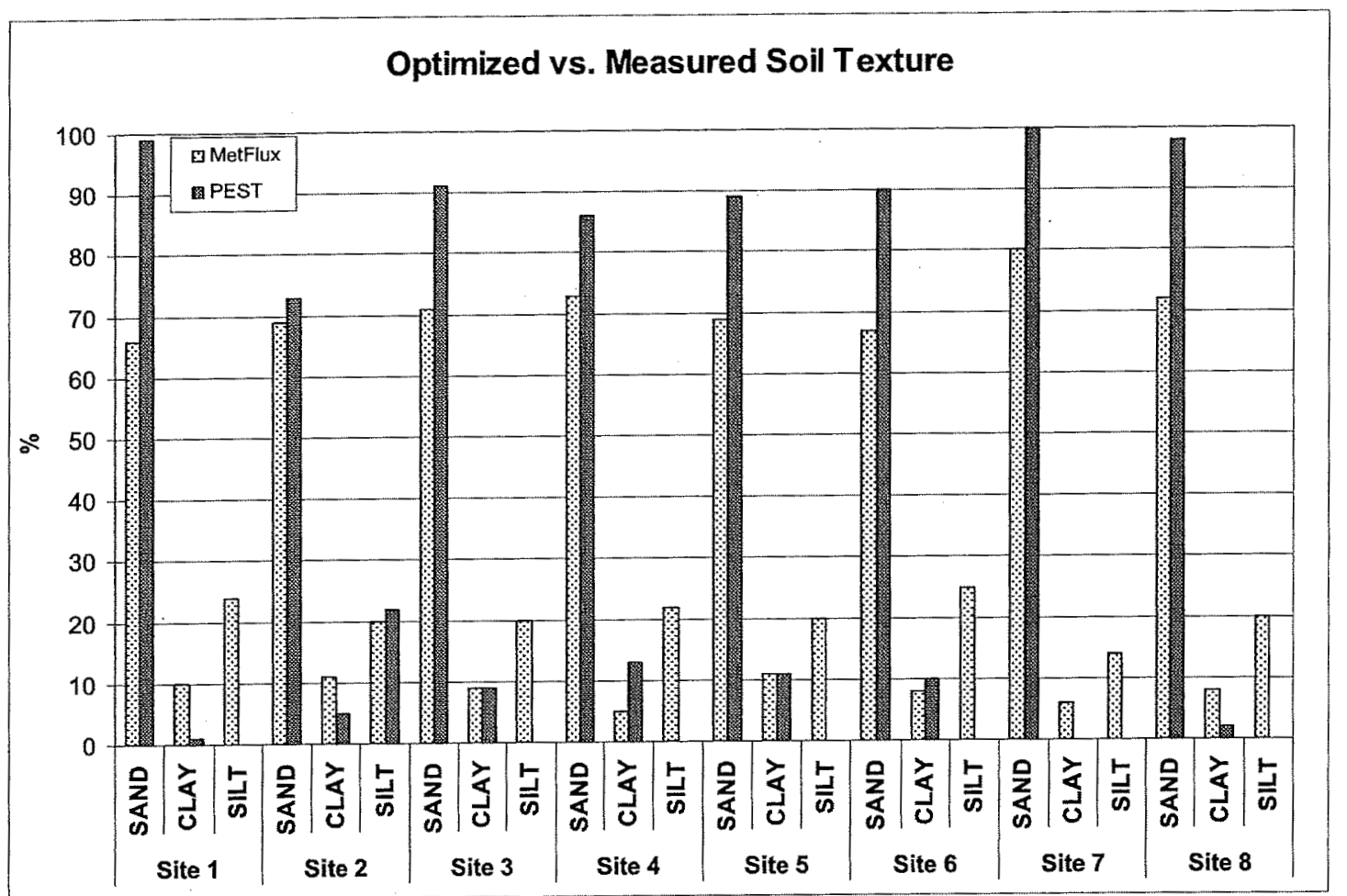

Figure 5: Percentages of sand, silt, and clay estimated by PEST-Noah at the eight Metflux sites compared with in-situ measurements from Schmugge et al. (1994). 
a)

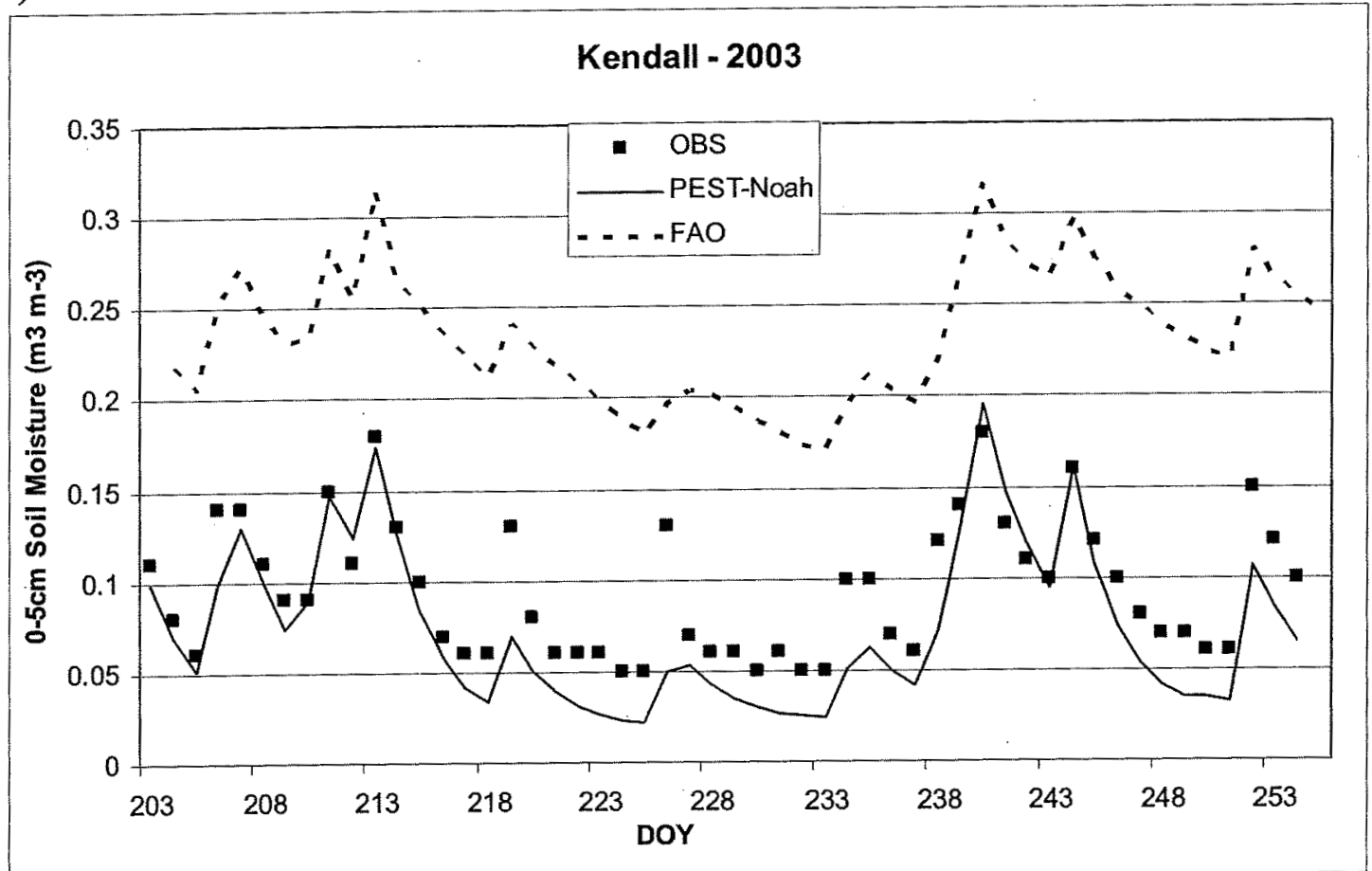

b)

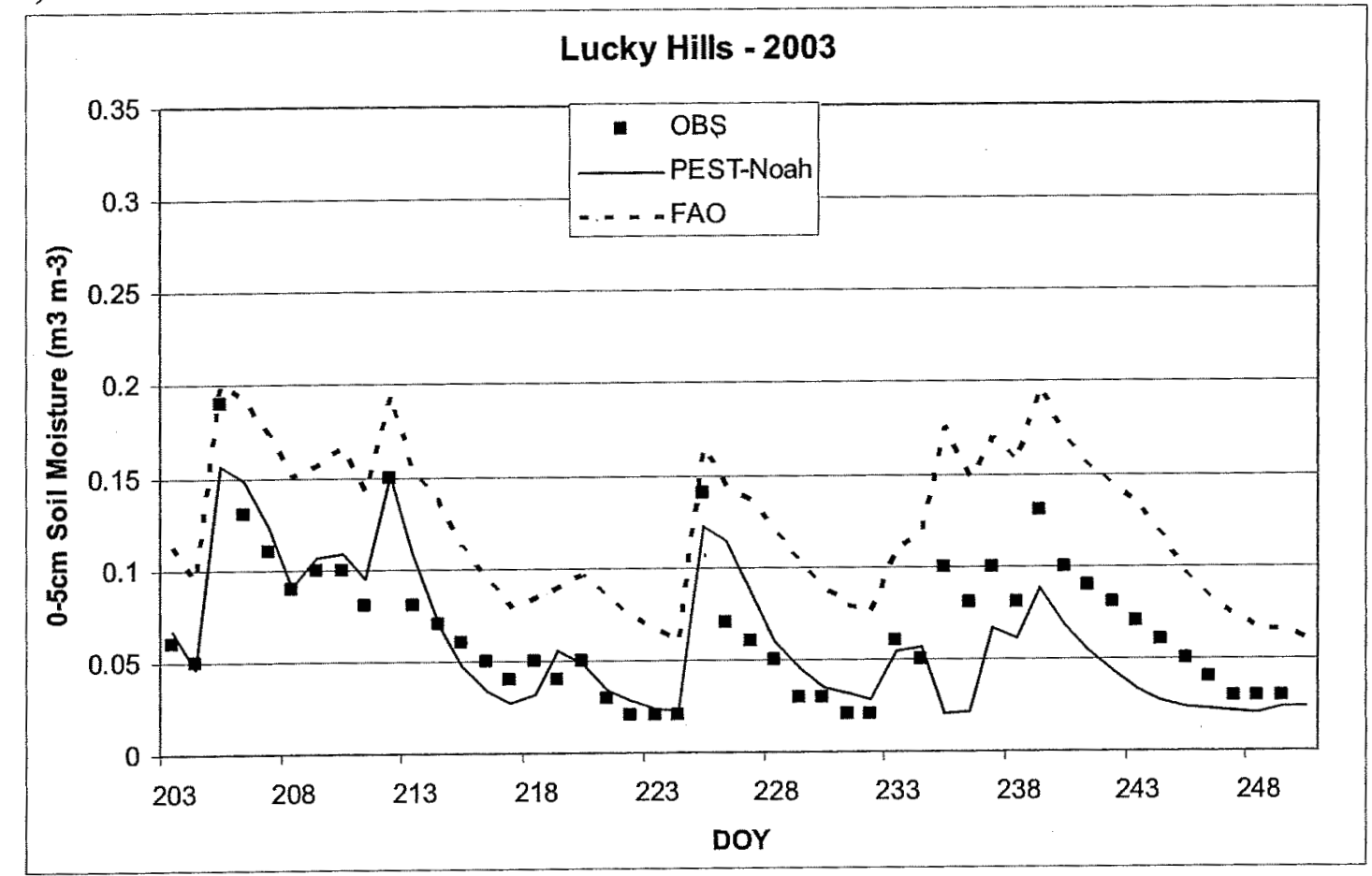

Figure 6: Near-surface soil moisture simulated by Noah using PEST-derived soil properties and default soil parameters (FAO) compared against Vitel probe observations at the a) Kendall and b) Lucky Hills sites during summer 2003. 
a)

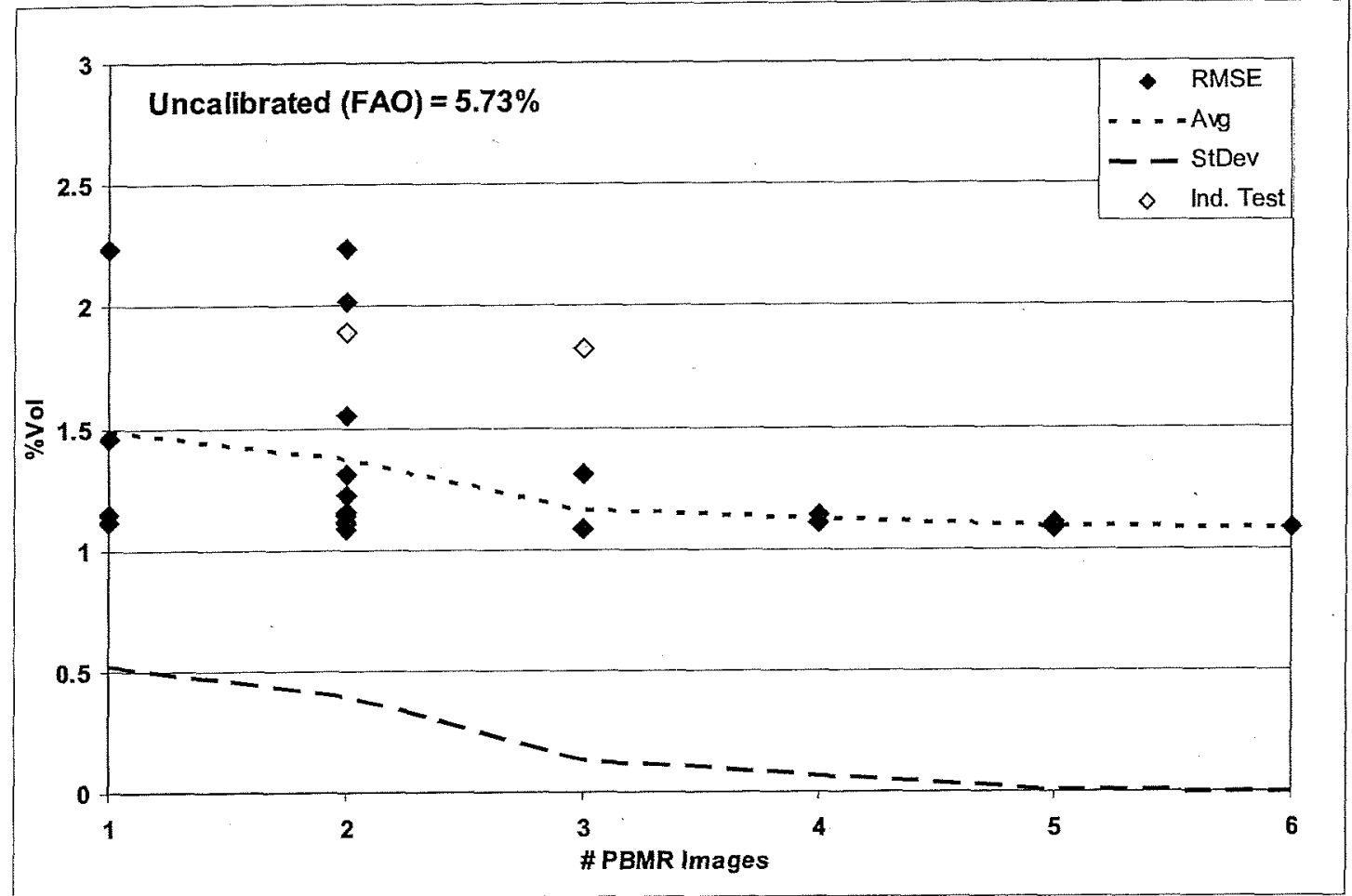

b)

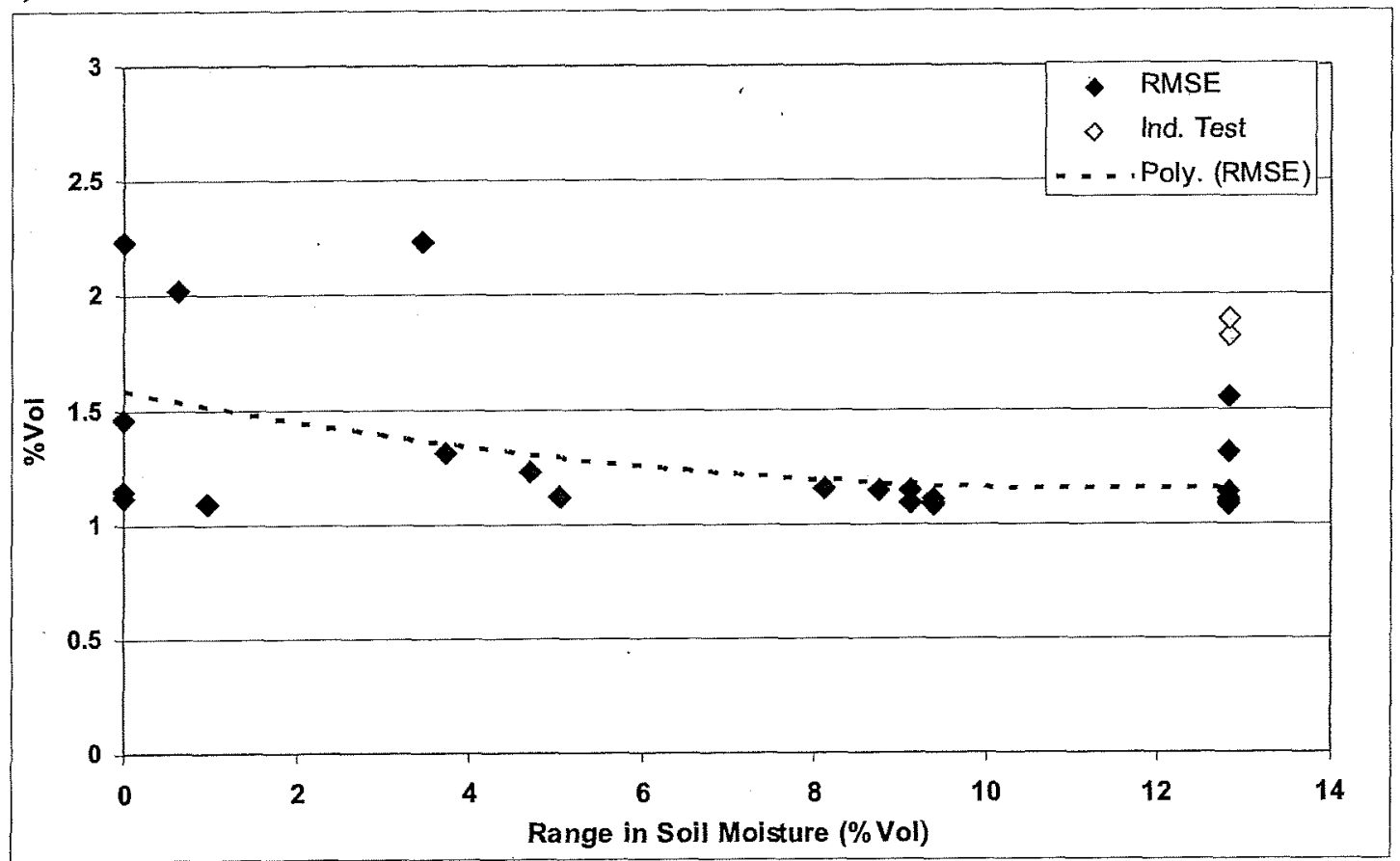

Figure 7: Errors in simulated versus observed $0-5 \mathrm{~cm}$ soil moisture at the Kendall site for varying a) numbers of PBMR images used in PEST-Noah and b) ranges of soil moisture covered by these images. The lightly shaded points indicate simulations that were calibrated using only the first two and three PBMR images. 
a)

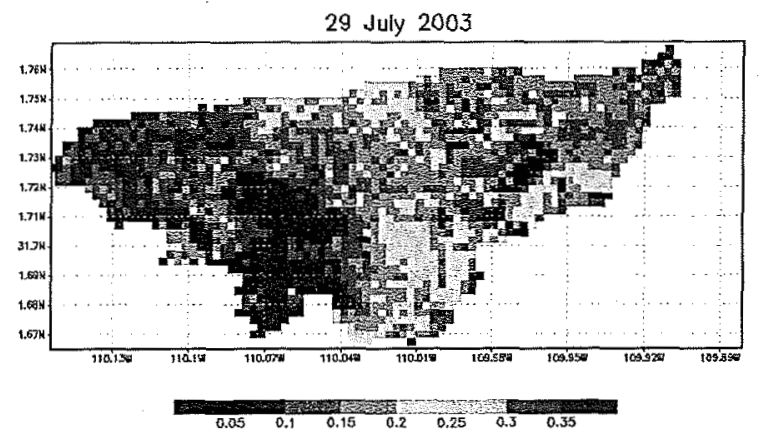

b)
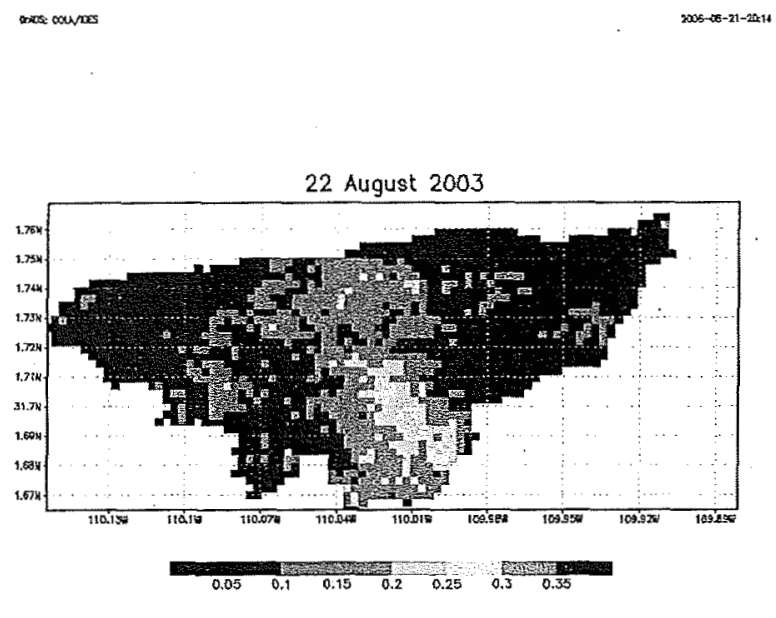

c)

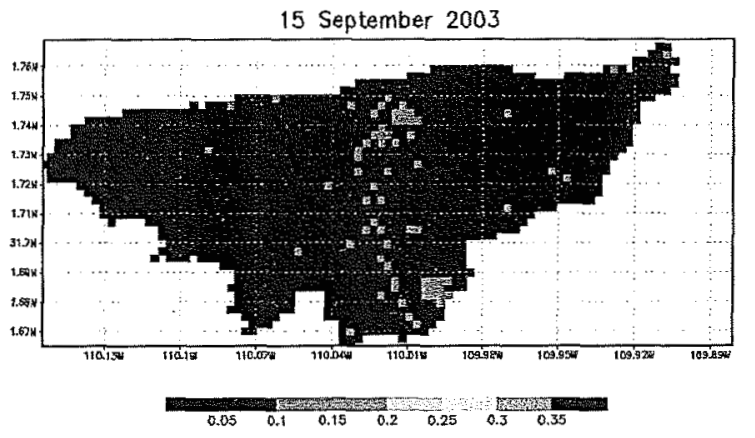

Figure 8: Soil moisture $\left(\mathrm{m}^{3} \mathrm{~m}^{-3}\right)$ estimated from RADARSAT-1 active microwave measurements over the WGEW on a) 29 July, b) 22 August, and c) 15 September 2003. Backscatter was aggregated from 7 to 280 meters to reduce the effects of speckle and converted to soil moisture using the delta index image differencing technique (Thoma et al. 2006). 
a)

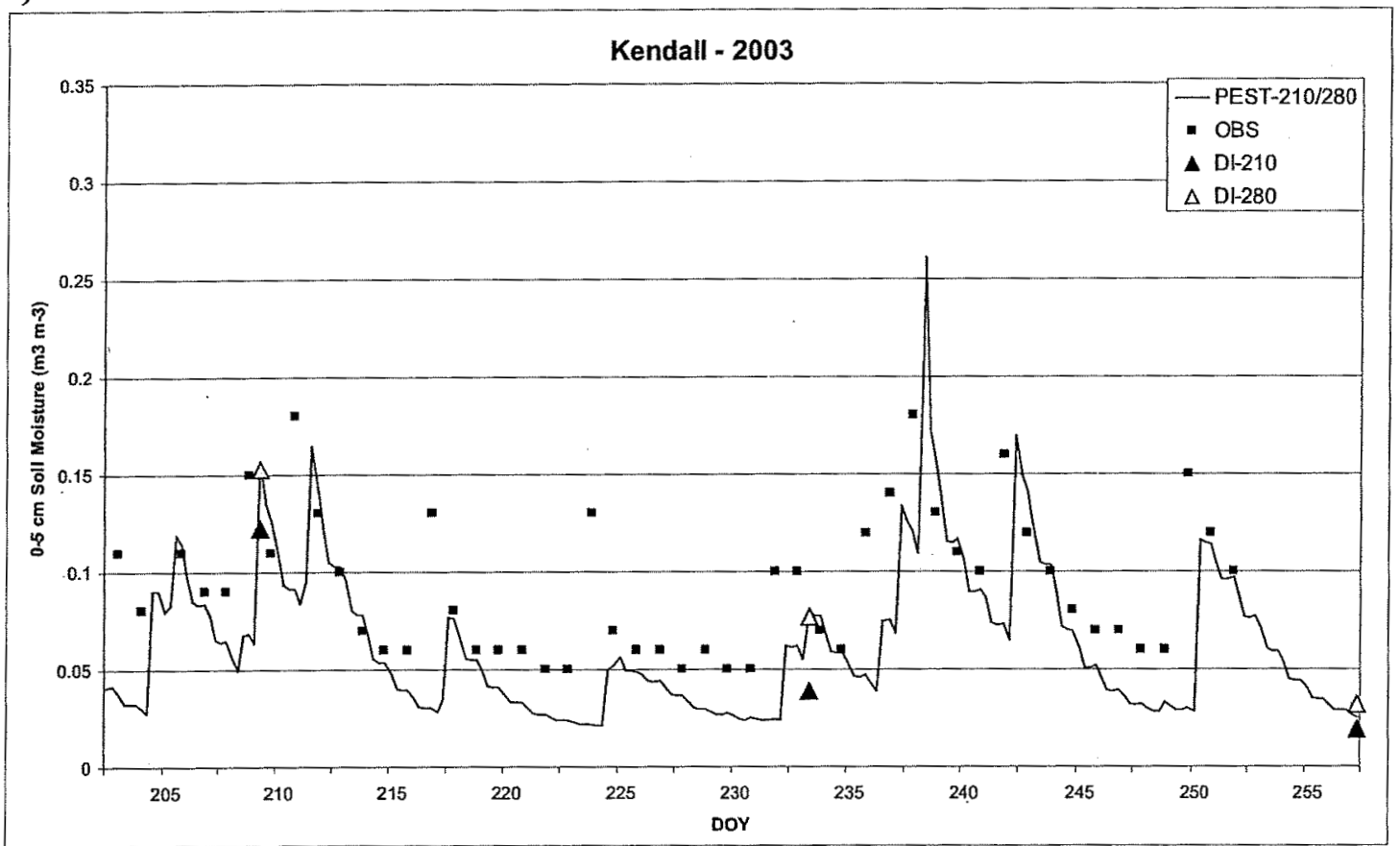

b)

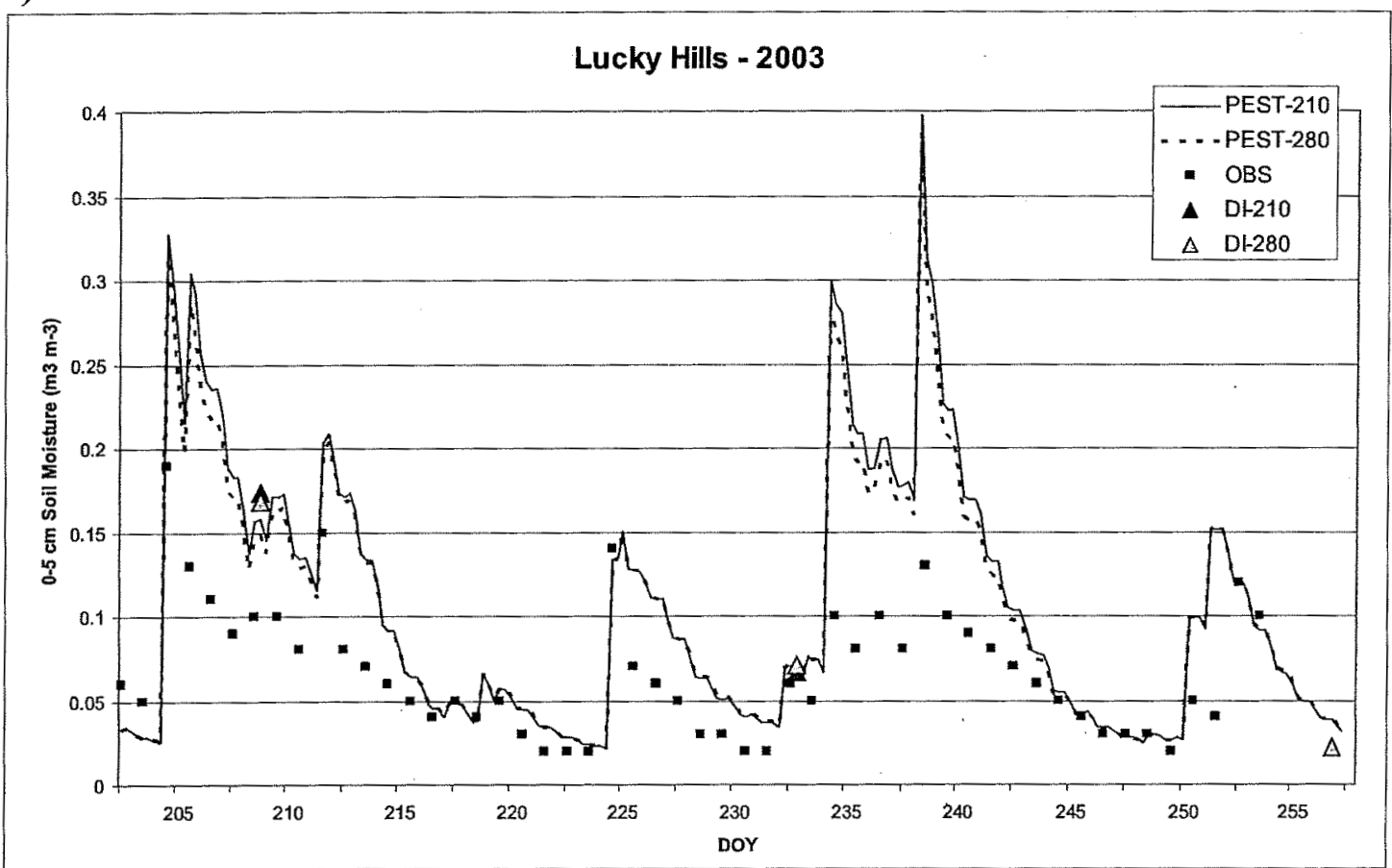

Figure 9: Near-surface soil moisture simulated by PEST-Noah using 210 and 280 meter Delta Index as observations at the a) Kendall and b) Lucky Hills sites during summer 2003. Also shown are observations of soil moisture from Vitel probes surrounding each location. 
a)

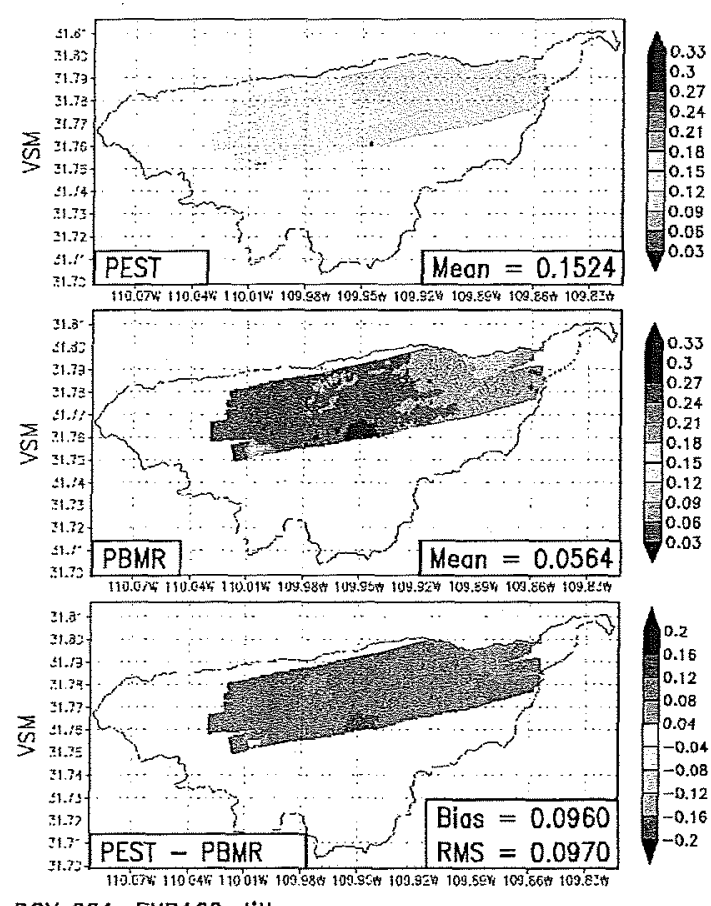

b)

DOY 221; EXP160; tit
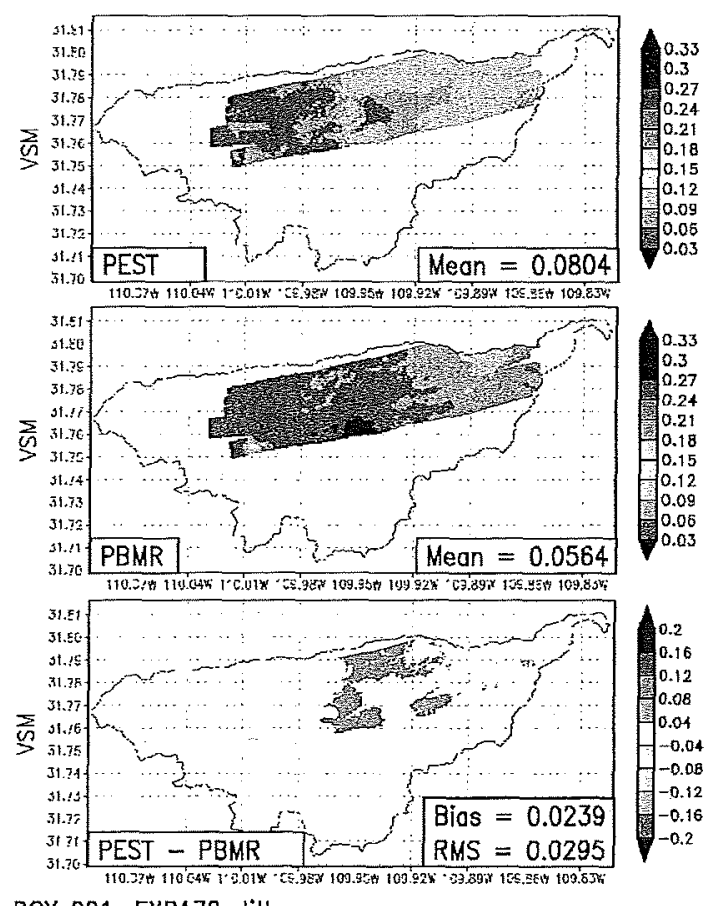

DoY 221; EXP170; tit!

Figure 10: RMSE and bias in simulated versus observed $0-5 \mathrm{~cm}$ soil moisture using a) default (FAO) soils and b) soil properties optimized using PEST-Noah on DOY 221. A single set of parameters were optimized for the entire PBMR domain. 